NBER WORKING PAPER SERIES

\title{
SKILLED IMMIGRATION AND THE EMPLOYMENT STRUCTURES OF U.S. FIRMS
}

\author{
Sari Pekkala Kerr \\ William R. Kerr \\ William F. Lincoln \\ Working Paper 19658 \\ http://www.nber.org/papers/w19658 \\ NATIONAL BUREAU OF ECONOMIC RESEARCH \\ 1050 Massachusetts Avenue \\ Cambridge, MA 02138 \\ November 2013
}

Comments are appreciated and can be sent to wkerr@hbs.edu. We especially thank Daniel Goroff and the Sloan Foundation for financial support for this project; we thank Daron Acemoglu, George Borjas, Prithwiraj Choudhury, Jim Davis, Gilles Duranton, Lee Fleming, Bronwyn Hall, Ron Hira, Larry Katz, Andrei Levchenko, Norm Matloff, Paul Oyer, Giovanni Peri, Jagadeesh Sivadasan, two referees, and seminar participants at American Economic Association 2013 Meetings, APPAM Fall 2012 Research Conference, Brandeis School of Business, Harvard University, Harvard Business School, John Hopkins SAIS, London Business School, London School of Economics, NBER 2012 Conference on High-Skill Immigration, NBER Productivity, Northeastern University, Research Institute of Industrial Economics, Richard Ivey School of Business, Rutgers Business School, Society of Labor Economics 2013 Meetings, University of California Berkeley Haas School of Business, University of Pennsylvania Wharton School, and Wellesley College for very helpful comments; and we thank Alexis Brownell and Christine Huang for excellent research assistance. William Kerr is a research affiliate of the Bank of Finland and thanks the Bank for hosting him during a portion of this project. The research in this paper was conducted while the authors were Special Sworn Status researchers of the US Census Bureau at the Boston Census Research Data Center (BRDC). Support for this research from NSF grant ITR-0427889 is gratefully acknowledged. Research results and conclusions expressed are the authors' and do not necessarily reflect the views of the Census Bureau or NSF. This paper has been screened to ensure that no confidential data are revealed. The views expressed herein are those of the authors and do not necessarily reflect the views of the National Bureau of Economic Research.

NBER working papers are circulated for discussion and comment purposes. They have not been peerreviewed or been subject to the review by the NBER Board of Directors that accompanies official NBER publications.

(C) 2013 by Sari Pekkala Kerr, William R. Kerr, and William F. Lincoln. All rights reserved. Short sections of text, not to exceed two paragraphs, may be quoted without explicit permission provided that full credit, including (C) notice, is given to the source. 
Skilled Immigration and the Employment Structures of U.S. Firms

Sari Pekkala Kerr, William R. Kerr, and William F. Lincoln

NBER Working Paper No. 19658

November 2013

JEL No. F15,F22,J44,J61,O31,O32

\title{
ABSTRACT
}

We study the impact of skilled immigrants on the employment structures of U.S. firms using matched employer-employee data. Unlike most previous work, we use the firm as the lens of analysis to account for a greater level of heterogeneity and the fact that many skilled immigrant admissions are driven by firms themselves (e.g., the H-1B visa). OLS and IV specifications find rising overall employment of skilled workers with increased skilled immigrant employment by firm. Employment expansion is greater for younger natives than their older counterparts, and departure rates for older workers appear higher for those in STEM occupations compared to younger worker.

\author{
Sari Pekkala Kerr \\ Wellesley College \\ 106 Central Street \\ Wellesley, MA 02481 \\ skerr3@wellesley.edu \\ William R. Kerr \\ Harvard Business School \\ Rock Center 212 \\ Soldiers Field \\ Boston, MA 02163 \\ and NBER \\ wkerr@hbs.edu
}

\author{
William F. Lincoln \\ School of Advanced International Studies \\ The Johns Hopkins University \\ 1717 Massachusetts Ave NW, Suite 708 \\ Washington, DC 20036 \\ wlincoln@jhu.edu
}




\section{Introduction}

The immigration of skilled workers is of deep importance to the United States. In 2008, immigrants represented $16 \%$ of the U.S. workforce with a bachelor's education, and they accounted for $29 \%$ of the growth in this workforce during the 1995-2008 period. In occupations closely linked to innovation and technology commercialization, the share of immigrants is even higher at almost 24\%. As the U.S. workforce ages and baby boomers retire, the importance of skilled immigration has the potential to increase significantly. Perhaps due to this impact, the appropriate policies and admissions levels for skilled workers remain bitterly debated. Many advocates of higher rates of skilled immigration have recently adopted the phrase "national suicide" to describe the limited admissions of skilled workers compared to low-skilled immigrants to the United States. On the other hand, expansions of admissions are passionately opposed by critics who believe that skilled immigration is already too high.

This study analyzes how the hiring of skilled immigrants affects the employment structures of U.S. firms. Our focus on the firm is both rare and important. From an academic perspective, there is very little tradition for considering firms in analyses of immigration. As one vivid example, the word "firm" does not appear in the 51 pages of the classic survey of Borjas (1994) on the economics of immigration, and more recent surveys also tend to pay little attention to firms. As described in greater detail below, economists instead typically approach immigration through the conceptual framework of shifts in the supply of workers to a labor market. Firms provide some underlying demand for workers, but their role is abstracted from. Much of the debate in the literature is then about what constitutes the appropriate labor market and how its equilibrium is determined.

While this approach is perhaps the correct lens for low-skilled immigration, it seems quite incomplete for skilled migration. First, the structure of many skilled immigration admissions is designed in part to allow companies to select the workers that they want to hire, rather than migrants being selected by the U.S. government. It thus seems particularly valuable to understand the impact of these admissions on the firms themselves. A firm-level analysis also allows us to account for heterogeneity that is not captured with other approaches. This is especially important since firms hold specific assets that are often instrumental in determining employment outcomes and their organizational structures more generally. The development of new employer-employee data offers great promise for expanding our understanding of the immigration process from both empirical and theoretical perspectives. The literature on international trade, for example, has benefitted deeply in recent years from greater consideration of the role of the firm.

While our analysis is about skilled immigration more generally, a prime example of the legal role that firms play in skilled immigration is the $\mathrm{H}-1 \mathrm{~B}$ visa, which is the largest program for temporary skilled immigration to the United States. The H-1B is a firm-sponsored visa, meaning that a company first identifies the worker that it wants to hire and then applies to the 
U.S. government to obtain the visa. Once the work has started, the immigrant is effectively tied to the firm until obtaining permanent residency or obtaining another visa. This lock-in effect is particularly strong if the firm further sponsors the immigrant for permanent residency. Moreover, most of the arguments in the public debate about the impact of skilled immigration in the United States are also firm-level statements. For example, in the context of the H-1B, Bill Gates has stated in congressional testimony that Microsoft hires four additional employees to support each worker hired on the visa. On the other hand, Matloff (2003) argues that U.S. companies hire skilled immigrants through the $\mathrm{H}-1 \mathrm{~B}$ program to displace older citizen workers with high salaries, thereby lowering their cost structures, and presents case studies about displacement within individual firms. Other examples are National Foundation for American Policy (2008, 2010) and Hira (2010).

Given this context, this paper looks at the role of young skilled immigrants within the firm. We focus on the immigration of young workers as they account for a large portion of skilled immigrants; for example, $90 \%$ of $\mathrm{H}-1 \mathrm{~B}$ workers are under the age of 40 . This is likely due to the characteristics of firm demand as well as the preferences of foreign workers to immigrate when they are young. At the center of this project is a confidential database maintained by the U.S. Census Bureau called the Longitudinal Employer-Household Dynamics (LEHD) database. Sourced from required state unemployment insurance reporting, the LEHD provides linked employer-employee records for all private sector firms in 29 covered states. Among the information included for each employee is the worker's quarterly salary, age, gender, citizenship status, and place of birth. This wealth of information allows us to observe directly the hiring of skilled immigrants and the associated changes in firm employment structures (e.g., the hiring or departures of skilled U.S.-born workers over the age of 40).

From the LEHD data set, we develop an unbalanced panel of 319 firms over the 1995-2008 period. Our selection criteria emphasize top employer firms and top patenting firms in the United States, given that much of the discussion of the effects of skilled immigration focuses on employment outcomes, innovation rates, and the high-tech sector in particular. Given the skewness of the firm size distribution (Axtell, 2001; Gabaix, 2011), our sample accounts for $10 \%-20 \%$ of the workforce in covered states (including over 67 million employees in total during the period) and about $34 \%$ of U.S. patenting. We construct an annual panel that describes the employment and hiring of skilled immigrants and use the panel to quantify the link between young skilled immigration and firm employment structures.

Ordinary least squares (OLS) estimations find a strong link between expansions in a firm's young skilled immigrant employment, where young workers are defined as those under 40 years old, and expansions in other parts of the firm's skilled workforce. With this framework, we estimate that a $10 \%$ increase in a firm's young skilled immigrant employment correlates with a $6 \%$ increase in the total skilled workforce of the firm. Expansion is evident and mostly balanced for older and younger native skilled workers. Increases of a similar magnitude are also found 
for the firm overall, including lower-skilled workers, with the firm experiencing a small increase in the skilled worker share. Similar elasticities are evident on the hiring margin itself - that is, looking at the relationship between changes in the rates at which immigrant and native groups are hired within a year. We quantify effects through a first-differenced framework that removes permanent differences across firms and includes multiple controls in the spirit of other approaches to studying immigration.

OLS estimations are potentially biased by omitted factors, measurement error in immigrant hiring, or measurement error induced by corporate restructurings. We thus turn to instrumental variable (IV) estimations that use national changes in the $\mathrm{H}-1 \mathrm{~B}$ visa program's size over the 1995-2008 period interacted with how important H-1B workers are for each firm. While our focus is more broadly on skilled immigration, the H-1B program's substantial size provides useful identifying variation for understanding these impacts. National changes in the H-1B program's size are measured through annual population estimates developed by Lindsey Lowell or through summations of recent $\mathrm{H}-1 \mathrm{~B}$ visa caps. Our first instruments measure the dependencies of firms by their Labor Condition Applications (LCAs), a first step towards applying for H-1B visas. We also develop alternative dependency measures through the initial shares of each firm's skilled workforce that come from Chinese and Indian economies or that are employed in Science, Technology, Engineering, and Mathematics (STEM) occupations.

We present our IV estimations in two ways. A first set of estimations does not place any structure on the underlying growth process of the firm. With this approach, we only have valid instruments using the $\mathrm{H}-1 \mathrm{~B}$ population trend to model national changes (but not the summation of recent visa caps), and even these estimations are sensitive to specification choice. These limits are not too surprising given that we are attempting to predict annual changes in relative hiring by firms over a 14-year period. As a second approach, we provide greater structure to the underlying growth dynamics of firms by controlling for contemporaneous changes in their medium-skilled workforces, a group of workers mutually exclusive from the skilled workforce and defined precisely below. In these latter estimations, we can no longer examine total firm size as an outcome, but we are able to quantify changes in skilled workforce composition. This second approach offers greater alternatives for instrument design and facilitates many extensions. These IV analyses of the skilled worker composition thus form the centerpiece of this study's findings and where we place our emphasis.

Within these empirical boundaries, the IV estimations deliver several consistent results. First, the IV estimations generally agree with OLS that the overall skilled component of the firm's workforce expands with greater employment of young skilled immigrants. Moreover, the IV estimations consistently find that this expansion comes disproportionately through young skilled native workers and older skilled immigrant workers as opposed to older native workers. While OLS estimations find increases in the immigrant share of the firm and shifts towards younger skilled workers, the IV estimations suggest that OLS underestimates the extent of these changes. 
The decline in the older worker share is again not solely due to the mechanical effect of employing more young skilled immigrants, as we also find a relative decline for older workers among native employees only.

To summarize, we find evidence that increased employment of young skilled immigrants raises the overall employment of skilled workers in the firm, increases the immigrant share of these workers, and reduces the older worker share of skilled employees. The latter effect is evident even among natives only. As to whether the older worker skilled employment increases or declines in absolute level, the evidence is mixed but suggests that absolute declines are not likely. These estimates suggest that age is an important dimension on which firms make decisions and that there may be lower complementarity between young skilled immigrants and older domestic workers. This finding is consistent with some of the arguments made in the public debate about skilled immigration and suggests that age is an important dimension along which immigration may have heterogeneous impacts. The particular direction of these findings is not obvious ex ante (e.g., one could have imagined the highest complementarity existing between the seasoned experience of older natives and the technical skills of young immigrants). Finally, OLS results consistently find that the overall size of the firm increases with higher employment of young skilled immigrants, but the IV estimates are inconclusive on this dimension.

Building on these results, we consider an extension to our primary estimations by looking at employment effects across occupations. The Current Population Survey (CPS) collects employment data from a random group of workers in the U.S. economy in each year. A bridge has been established between the 1986-1997 CPS and the LEHD. While our sample period mostly comes after this link is available, we are able to ascertain the primary occupations of over 25,000 workers in our firm sample at the time of their inclusion in the CPS survey. This platform allows us to evaluate whether workers linked to occupations related to STEM exhibit different responses when skilled immigration increases. As we show below, this might be true because the elasticity of substitution by worker age in these occupations is higher than in other fields. Our evidence is suggestive on this dimension. On one hand, there is a higher departure rate of older workers in STEM occupations with greater young skilled immigration into the firm. This heightened oldyoung differential is especially pronounced for workers earning over $\$ 75,000$ a year. On the other hand, while the coefficients for older workers in STEM occupations are higher than for older workers in non-STEM occupations, the magnitude of the differences between these estimates are not statistically significant or economically large. Breaking down the results across occupations to the extent feasible with our data, relative departure rates for older workers appear higher in STEM occupations, reflective of the high age elasticity of substitution in this field.

These results provide a multi-faceted view of how young skilled immigration shapes the employment structures of U.S. firms. Interestingly, these results do not align with any single popular account and suggest that greater caution in public discourse is warranted. The next section of this paper reviews some of the literature on the impacts of immigration and discusses 
a conceptual framework that motivates our empirical specification. Section 3 presents a description of our employment data, and Section 4 discusses our OLS employment analyses. Our IV estimations are then presented in Section 5. Section 6 discusses our occupational results, and the final section concludes.

\section{Literature Review and Conceptual Framework}

Firms are mostly absent from the literature on the impact of immigration. Instead, economists have sought to define labor markets and then model immigration as an adjustment in the potential supply of labor to that market. A natural consequence of this approach has been a debate about what constitutes the appropriate labor market. Even more debate and research has followed about related questions like: Do natives move out of the labor markets in response to immigration (and thereby dampen the supply increase)? How quickly do other factors of production, like capital or technology, respond to labor inflows (and thereby alter relative price effects)? What are the non-employment effects of immigration? These and similar questions have typically been directed toward general immigration and so are not reviewed here. ${ }^{1}$ We instead focus on the initial question by outlining the approaches past work has taken for defining the labor market, identifying skilled immigration studies that follow each approach, and describing how the perspective of a firm may be captured or not.

A first approach defines labor markets as local areas like cities or states and is most closely associated with the analysis of Card (2001). With this lens, immigrants to Boston are thought to most directly impact the opportunities of natives currently living in Boston, with less emphasis on other attributes like the relative ages of workers. Kerr and Lincoln (2010), Hunt and GauthierLoiselle (2010), and Peri et al. (2013) are examples of this approach with respect to skilled immigration and innovation. ${ }^{2}$ To the extent that a firm makes employee choices within a single local area, either because the firm is relatively small or because local units have high autonomy, then the behavior of the city at large may be reflective of the underlying firms. One possible limitation with respect to the firms we study is the fact that our firms typically extend across multiple geographic areas.

Another approach, most closely associated with Borjas (2003), instead describes a national labor market among workers with similar education and age/experience profiles. With this lens, a 25-year-old immigrant with a bachelor's education in San Francisco may affect the opportunities of a 25-year-old native graduating from college in Boston. Moreover, this effect may be larger than the effects of competition from older natives of a similar level of education who also live in

\footnotetext{
${ }^{1}$ General surveys of the immigration literature include Borjas (1994), Friedberg and Hunt (1995), Freeman (2006), Dustmann et al. (2008), and Kerr and Kerr (2011). An incomplete list of some of the most recent work more generally includes Lewis (2011), Cortes (2008), Lach (2007), and Lubotsky (2007). Kerr (2013) reviews the high-skilled immigration empirical literature.

${ }^{2}$ Examples of studies using this approach for broader immigration patterns include Card (1990), Hunt (1992), and Peri $(2011,2012)$. Longhi et al. (2005, 2006) provide meta-reviews.
} 
Boston. While there are reasons to suspect that the labor market for highly educated workers is broad in spatial scope, this approach has not been used for analyzing skilled immigration. This is in large part due to the fact that the highest education group in these frameworks is typically a bachelor's education or greater - a level which is usually taken as the starting point for defining skilled immigration.

The age-education framework also does not capture elements of the hiring decision given that firms optimize over a full wage bill, internalizing potential complementaries across worker groups. And while the displacement effects identified by Borjas (2003) are frequently cited by critics of skilled immigration, some of their strongest claims rest on substitution margins that this basic framework does not allow. ${ }^{3}$ One notable example is the argument made by Matloff (2003) that firms' usage of the H-1B visa is primarily about a worker's age. Matloff proposes that the $\mathrm{H}-1 \mathrm{~B}$ program offers firms two types of potential savings. One type of savings centers on the fact that a 25-year-old Indian H-1B programmer might be paid less than a 25-year-old American programmer. He argues that this emphasis is entirely misplaced and that the real savings to the firm come instead from displacing a 50-year-old American programmer whose salary has grown with time. More generally, firms may have internal personnel policies (e.g., wage ladders with tenure) that interact with immigration. Firms and workers may also have implicit contracts or expectations that can be fortified or broken (e.g., Schleifer and Summers 1988).

A third approach, which is less common generally but important for the analysis of skilled immigration, considers labor markets to be specialized fields of study or expertise (e.g., Friedberg, 2001). Examples of this work with respect to skilled immigration include Borjas and Doran's (2012) study of the migration of Russian mathematicians following the Soviet Union's collapse and Moser et al.'s (2012) study of Jewish scientist expellees from Nazi Germany. This work again partially captures the firm's economics and partially does not. For example, the Borjas and Doran (2012) study is set in an institutional environment with limited room for overall growth and mostly lacking complementary inputs. Firms, which are often engaged in global competition, frequently suggest that the skilled immigrants they seek are necessary to grow the firm. In contrast to the substitution argument, this view suggests that skilled immigrants possess complementarities with domestic workers that can unlock greater opportunities. Moreover, firms tend to have greater flexibility than other institutions in the speed with which they can adjust their scale and worker composition, suggesting that their responses may differ from those measured across university departments. ${ }^{4}$

\footnotetext{
${ }^{3}$ Recent work builds more nesting into these models (e.g., Ottaviano and Peri 2012, Borjas et al. 2012).

${ }^{4}$ Borjas $(2005,2006)$ and Chellaraj et al. (2008) examine the impact of immigrant graduate students on natives. Stephan and Levin (2001), Hunt (2011, 2012), Hayes and Lofstrom (2012), Mithas and Lucas (2010), and Gaule and Piacentini (2012) assess quality differences between immigrants and natives with respect to innovation. Firm-level studies on skilled immigration include Kerr and Lincoln (2010), Clemens (2012), Foley and Kerr (2013), and Kerr et al. (2013). Broader work that examines general immigration using the LEHD includes Andersson et al. (2009, 2012). Olney (2012) considers how firm counts increase when immigration shocks impact a city. Work outside of the United States includes Nathan (2011), Barth et al. (2012), Åslund et al. (2012), Choudhury (2012), and Ozden and Wagner (2013).
} 
Turning from the academic literature, much of the discussion in the public debate over skilled immigration revolves around arguments over whether skilled immigrants are complements or substitutes for citizen workers. In popular accounts, this is frequently expressed as cost minimization versus access to scarce resources/skills. These views are often expressed by employees who claim to be displaced: workers feel they are being dismissed so that the firm can save money, the firm argues that the true issue is that the immigrant has scarce skills that would complement other workers' skills, the displaced worker debates how scarce that skill really is, and so on.

For the most part, this study does not observe the occupations of workers and so to an important degree we are not able to analyze these issues as precisely as we would like. Moreover, to the extent that we observe occupations in Section 6, the level of detail is too coarse to settle definitively the claims made in the public debate (e.g., discussions about computer programmer substitution are often about specific computer languages and how quickly one can or cannot learn these languages). Our study instead represents a broader inquiry into the patterns of hiring and employee departures associated with greater employment of skilled immigrants. By separating the dimensions of employee hiring and employee departures, we can shed some light on the activity that lies behind net employment changes for firms. We can ascertain whether some skilled employees are being hired, perhaps due to complementary skills. For example, Peri and Sparber $(2009,2011)$ emphasize how skilled immigrants can specialize in occupations demanding quantitative and analytical skills, while native workers take on occupations requiring interactive and communication skills. Other studies emphasize the benefits of diversity (e.g., Nathan 2011, Parrotta et al. 2013). And we can similarly identify when others are departing, perhaps due to displacement in some form. While interpretation of these margins should be cautious, they provide substantially greater information than previously available..$^{5,6}$

To gain some simple intuition for our empirical approach, we utilize a conceptual model from Desai et al. (2009). The original application of this model was for cross-border employment in U.S. multinationals, but a similar set of conditions represents one way to motivate our empirical specification. The model considers a firm that makes output using two types of labor - domestic and immigrant - with the concave production function $Q=Q\left(L_{D}, L_{I}\right)$. Increases in the employment of either group have a diminishing effect on output levels, holding the other fixed $\left(\partial Q / \partial L_{D}>0, \partial^{2} Q / \partial L_{D}^{2}<0, \partial Q / \partial L_{I}>0, \partial^{2} Q / \partial L_{I}^{2}<0\right)$. Our focus is on the cross-elasticity $\partial^{2} Q / \partial L_{D} \partial L_{I}$

\footnotetext{
${ }^{5}$ We will also study these complementarity differences by worker age, which has been far less developed theoretically or empirically. One can, for example, easily imagine that older native workers with deep experience could best complement younger skilled immigrants. An alternative hypothesis would be that the interface is best between similar age groups (e.g., a young marketing team that best works with innovative technical products developed by skilled immigrants). We do not have a strong ex ante hypothesis about these relative effects.

${ }^{6}$ While this focus on the firm is an important step, the hiring of skilled immigrants likely has spillovers outside of the firm's boundaries. One employment-related example is how a firm's hiring decision and revelations of information about employees enrich future labor pools from which all firms draw (e.g., Tervio 2009, Pallais 2011). The conditions are in fact one reason why tied employment relationships exist with the H-1B program. While spillovers are important, the choice of firms to hire immigrants depends most on their own economics, and so an accurate portrait of these conditions is needed and the subject of the study.
} 
The concave revenue function of the firm is $R(Q, y)$, with $y$ representing economic conditions exogenous to the firm (e.g., price levels). The firm maximizes $R(Q, y)-c_{D} L_{D}-c_{I} L_{I}$, where $c_{D}$ is the cost for domestic workers and $c_{I}$ is the cost for immigrant workers. This leads to the familiar conditions for profit maximization that

$$
\frac{\partial R}{\partial Q} \frac{\partial Q}{\partial L_{D}}=c_{D} \text { and } \frac{\partial R}{\partial Q} \frac{\partial Q}{\partial L_{I}}=c_{I}
$$

In this model, a reduction in the cost of employing an immigrant $d c_{I}$ increases the employment of immigrants in the firm. This expansion in turn affects the employment of domestic workers through the concavity of the output and revenue functions. This can be seen by totally differentiating the first expression in (1). Denote the change in immigrant employment by $d L_{I}$, and the induced change in domestic employment by $d L_{D}$. The total differentiation is

$$
\frac{\partial Q}{\partial L_{D}} \frac{\partial^{2} R}{\partial Q^{2}}\left[\frac{\partial Q}{\partial L_{D}} d L_{D}+\frac{\partial Q}{\partial L_{I}} d L_{I}\right]+\frac{\partial R}{\partial Q}\left[\frac{\partial^{2} Q}{\partial L_{D}^{2}} d L_{D}+\frac{\partial^{2} Q}{\partial L_{D} \partial L_{I}} d L_{I}\right]+\frac{\partial Q}{\partial L_{D}} \frac{\partial^{2} R}{\partial Q \partial y} d y=d c_{D}
$$

We make two important assumptions. First, we assume that $d c_{D} / d L_{I}=0$. This is equivalent to assuming that immigration rates into the firm do not affect the employment costs of domestic employees. This is a fiercely debated topic, but the available empirical evidence suggests this assumption is plausible. For example, Kerr and Lincoln (2010) do not find any wage effects for domestic workers in a state-level analysis of expansions in the H-1B program. Second, we assume that $d y / d L_{I}=0$. The concept behind this assumption is that the firm's revenue function does not change contemporaneously with the change in immigrant employment costs. In our IV application, this represents the important empirical claim that the factors that reduce the immigrant employment cost are not correlated with factors changing the firm's profit function.

With these assumptions, we can rearrange the remaining terms in (2) to be

$$
d L_{D}=\frac{\left[\frac{\partial Q}{\partial L_{D}} \frac{\partial Q}{\partial L_{I}} \frac{\partial^{2} R}{\partial Q^{2}}+\frac{\partial R}{\partial Q} \frac{\partial^{2} Q}{\partial L_{D} \partial L_{I}}\right]}{-\left[\left(\frac{\partial Q}{\partial L_{D}}\right)^{2} \frac{\partial^{2} R}{\partial Q^{2}}+\frac{\partial R}{\partial Q} \frac{\partial^{2} Q}{\partial L_{D}^{2}}\right]} d L_{I} .
$$

The denominator on the right hand side of the expression (3) is positive given the properties of the revenue and production functions $\partial Q / \partial L_{D}>0, \partial^{2} R / \partial Q^{2}<0, \partial R / \partial Q>0$, and $\partial^{2} Q / \partial L_{D}^{2}<0$. The sign of the numerator in expression (3) hinges on the cross-elasticity term $\partial^{2} Q / \partial L_{D} \partial L_{I}$. The relationship between $d L_{D}$ and $d L_{I}$ will be positive only if $\partial^{2} Q / \partial L_{D} \partial L_{I}>0$ and is sufficiently large to offset the magnitude of the first term in the summation of the numerator. This makes sense intuitively - if domestic and immigrant worker employment are complementary and sufficiently strong to overcome the concavity of the output revenue functions, then we should see a positive relationship between growth in domestic employment and growth in immigrant employment in the data. 


\section{$3 \quad$ Firm-Level Employment Data}

In this section we provide a description of the data that we use for our analyses. We first discuss the construction of the Longitudinal Employer-Household Dynamics (LEHD) database, how we select the firms in our panel, our definitions of employee hiring and departures, and descriptive statistics on our sample. As the LEHD has not been used extensively in prior research, we detail a number of the choices that we make in constructing our sample.

\subsection{Firm Panel Selection}

Our employment records come from the LEHD database, which is housed by the U.S. Census Bureau. The LEHD contains linked employer-employee records for all private sector firms covered by state unemployment insurance reporting requirements. The LEHD does not contain public sector workers at present. There are currently 29 states participating in the LEHD database, and these states are indicated by the shaded areas in Figure 1. At present, the employment records for all states extend through 2008, but the starting dates differ by state. Our primary sample uses a balanced panel of 18 states that have reporting starting by 1995 . These states are indicated by a star in Figure 1 and they notably include big (and high-immigration) states like California, Florida, Illinois, and Texas. Examples of major states not included are New York, Michigan, and Pennsylvania.

Our sample of firms taken from the LEHD focuses on large U.S. employers and major U.S. patenting firms. We select these two facets of firm behavior as the criteria for choosing our firm sample since much of skilled immigration is for work in high-tech industries. It is also the case that employment and innovation outcomes are frequently emphasized in debates about skilled immigration to the United States. Throughout much of this paper, we analyze these two groups together as there is extensive overlap; where warranted, we also report separate results using variation across the major patenting firms only. We describe here the selection of our initial sample and the creation of composite firms that account for major corporate restructurings.

We identify major employers using a number of different sources. While our analysis mostly focuses on employee records contained in the LEHD data set, the partial state coverage of the LEHD data noted above raises conceptual challenges about how to best select firms. Our basic approach first develops a candidate firm list using nationally-based employment records and then restricts the sample to those candidate firms that satisfy a certain coverage ratio in LEHD states.

Our specific procedure starts with the Census Bureau's Longitudinal Business Database (LBD), which contains annual employment records for all establishments in the United States. We link the name of each establishment to the LBD from the Standard Statistical Establishment List. Aggregating to the firm level by summing across establishments, we compile the names of the top 100 employers in every year from 1990 to 2008. We also supplement this list with 
firm names that are not contained in the first step but that rank in the top 100 U.S. firms for worldwide sales or employment contained in Compustat over the full 1990-2008 period. We further include those listed as Fortune 200 companies in $2009 .^{7}$

For our major patenting firms, we first extract from filings downloaded from the United States Patent and Trademark Office the patent assignee names that account for more than $0.05 \%$ of patents applied for during the 2001-2004 period. Given that roughly half of USPTO patents are filed by foreign inventors and firms, we restrict our analysis to patents with inventors residing in the United States at the time of their USPTO application. We then identify these major patenting firms in the Census Bureau data. ${ }^{8}$

With this assembled list of names, we next define firms and collect the Census Bureau firm identifiers and the federal Employer Identification Number (EIN) associated with them. In many cases, there are multiple firm identifiers and EINs for these entities that we combine together. An alternative approach would be to use the Census Bureau firm identifiers from the top employment companies in the raw data. We use a manual approach in part due to the fact that we observe cases where the provided firm identifiers display irregular properties (e.g., employment shifting briefly to another entity and back). While labor intensive, our manual approach ensures very consistent firm definitions for both our top employers and major patenting firms.

We also use this manual approach as a means of accounting for major corporate restructurings. Our 1995-2008 sample period contains some significant mergers and acquisitions, corporate spin-offs, and similar events that can create discontinuous changes in firm employment patterns. To address this issue, we create composite firms that combine the records of both entities before and after the major corporate restructuring. For example, if two firms merge in 2001, we combine their records already in the 1995-2000 period. Unidentified restructurings will result in non-classical measurement error, with an empirical bias discussed below. This building of composite firms represented the longest data development step with the LEHD, but keeping the restructuring components separate before and after the event is not feasible or appropriate due to the resulting changes in employment reporting. ${ }^{9,10}$

\footnotetext{
${ }^{7}$ The additions with these latter two steps are fairly small in number, as most of these firms are picked up by the LBD employer name search directly. These steps ensure the robustness of the sample design for including major employer firms. We are also not allowed to disclose the names of the firms in our sample, but these publicly-available lists document the types of companies targeted.

${ }^{8}$ This patent assignee matching builds upon the prior work of Balasubramanian and Sivadasan (2011), Kerr and $\mathrm{Fu}$ (2008), and an internal Census Bureau report by Kaushik Ghosh and William Kerr. The list of included patenting firms does not depend much upon the years employed due to persistence in patenting rates, and we find a similar sample set when using patenting over the 1995-2008 period.

${ }^{9}$ We create these composite firms with a hinge date of 2005 . That is, if the corporate restructuring occurs in 2005 or prior, we combine the employer records. If the event falls after 2005, we do not correct for it by creating a composite firm but instead end the firm records one year prior to the event. The 2005 cutoff date balances the competing objectives of retaining firms that undergo significant restructuring but not mandating adjustments for very late restructurings in the sample period where it is simply better to treat the entities separately. The firms that we identify as undergoing significant restructurings are somewhat more likely to be related to STEM work, but we also see a significant number of these changes in other industries as well.

${ }^{10} \mathrm{On}$ average, the firms in our sample contain roughly 3.5 Census Bureau firm identifiers and 58 federal EINs. There is no one-to-one mapping between a Census firm identifier and what one might think of as "an individual firm" in our context. Companies have multiple firm identifiers, for example, due to past mergers and acquisitions,
} 
Following these steps, our initial list of companies contains 453 firms. This list is reduced to 319 firms due to the following exclusions: small employment share in the core 18 LEHD states (64), temporary help firm (19), merged entities (15), not reliably found in LBD or LEHD (11), and poor data quality (25). We discuss the first two exclusions in further detail shortly, and examples of the latter cases are intellectual property holding companies or companies with very severe jumps in employment that we are unable to explain by any events in the company history. Consistent with the fact that the firm size distribution is quite skewed, the final 319 firms account for a large share of economic activity. They contain 10\%-20\% of all employment spells in the LEHD, depending upon the state, and 20\%-30\% of all workers in the LEHD are employed by these firms at some point during the period of analysis. The sample also accounts for over one-third of U.S. patenting. The sectoral composition of the sample is approximately $30 \%$ manufacturing; 25\% wholesale and retail trade; $30 \%$ finance, insurance, real estate, and services; and $15 \%$ other sectors.

Returning to the exclusions, the most important relates to firm coverage in the core 18 LEHD states. We restrict our final sample to 319 composite firms that have at least $25 \%$ of their employment in the core 18 LEHD states. This threshold is calculated from the LBD, where we observe the full employment counts of each firm by state. This serves two purposes. First, it is important that the observed employment patterns represent a meaningful portion of the firm in order to have an accurate portrait of the firm's decisions. For example, as the LEHD lacks data on New York, it would not be appropriate to study two small establishments located in an LEHD state of a New York-based finance firm if these two establishments contained only $2 \%$ of the New York-based firm's overall employment. Second, as described in greater detail below, this approach limits the potential for within-firm relocations of workers to be erroneously categorized as hiring/departures.

We also exclude 19 temporary help agencies. These agencies have very different employment relationships, derive their demand from other firms, and often move workers across multiple clients in a short period. Potential job creation or displacement effects are most likely to occur in client firms. These dynamics are certainly worthy of study but are beyond the conceptual boundaries of this study. It is important to note that temporary help agencies constitute a significant portion of $\mathrm{H}-1 \mathrm{~B}$ visa demand, which this paper touches upon at various points. As such, our results should only be viewed as providing evidence about the subset of firms that we consider.

administrative reasons related to bankruptcy or other restructurings, and other reasons that are not obvious from the LBD or the LEHD alone. In many situations, this is skewed in that one Census firm identifier contains the vast majority of the firm's employment, with other identifiers having much smaller contributions. We consider a total of 154 restructuring events with our sample. 


\subsection{LEHD Employment Data Description}

We use the LEHD's Business Register Bridge (BRB) file to link in the employment records contained in the LEHD for these 319 firms. The primary basis in the LEHD for identifying employer-employee linkages is the State Employer Identification Number (SEIN) that identifies individual establishments. The BRB includes for each SEIN the associated federal EIN and Census Bureau firm identifier by year. From the BRB, we collect the SEINs that are associated with our firms at any point in time. This collection of complete SEIN records is important as firms occasionally change SEINs for reasons unrelated to our interests, and these legal adjustments could otherwise be confused with actual changes in the company's employment dynamics. With the collected SEINs, we then prepare the employment records for our firm sample. We need each SEIN to be uniquely associated with a firm, and therefore we research any overlapping identifiers and assign them to the appropriate company. On average, our composite firms contain roughly 200 SEINs; these firms account for $1 \%-3 \%$ of establishment-quarter records in the LEHD, depending upon the state. For each SEIN, the employer characteristics files provide the establishment's industry, county location, and total annual payroll and employment. We also collect the unique employee identifiers by SEIN, which are used to collect associated worker employment histories from the individual employment histories files.

In addition, the individual characteristics files contain important person-level information collected mainly through the Social Security Administration, Statistical Administrative Records system (StARS), and the Unemployment Insurance Administration. Information on personlevel characteristics contained in the LEHD include gender, date of birth, date of death, place of birth, citizenship, and race. The place-of-birth variable provides information on which country the person was born in, and we utilize this variation extensively below. We also use this variable for identifying immigrants. We can group workers as belonging to one of three categories: U.S. citizens from birth, naturalized U.S. citizens, and non-citizens. Among non-citizens, the data unfortunately do not distinguish temporary visa holders from permanent residents. We use these data to define a worker as an immigrant if they are a naturalized citizen or a non-citizen. Thus, while we use variation in the number of $\mathrm{H}-1 \mathrm{~B}$ visas in some of our estimations and this is the largest program for temporary skilled immigration to the United States, our analysis is more directly about the impact of young skilled immigration.

We merge these person-level characteristics into their quarterly employment histories that contain their total earnings by employer. Workers are then characterized as being "skilled" or "not skilled." Given the LEHD's limitations for describing worker education levels, we use a worker's long-term earnings to assign skill levels in our analysis. This approach has the benefit of capturing variation in unobservable characteristics that are not necessarily accounted for with a measure of educational attainment. Our primary wage threshold for describing a skilled worker is that the worker's median annual earnings over the 1995-2008 period exceeds $\$ 50,000$ in real 2008 dollars, and this threshold is held constant through the course of our analysis. To put 
the $\$ 50,000$ figure in perspective, the U.S. Citizenship and Immigration Services (USCIS) has reported that the 25th percentile of proposed H-1B worker salaries on approved petitions in 2005 was $\$ 43,000$, which represents $\$ 47,403$ in real 2008 dollars. We only consider workers aged 18-64 in our study. ${ }^{11,12}$

Our final step takes the assembled worker records and aggregates them to measure the employment composition of the company by year. The construction from the micro-data allows us to analyze several dimensions of a firm's workforce simultaneously (e.g., native workers over 40 years old earning $\$ 50,000)$. Our primary empirical approach considers firm-years as the unit of observation. For these analyses, we only include the 18 states present in the LEHD since 1995 for calculating employment patterns. Thus, we use a balanced state panel for drawing data while the firm panel itself is unbalanced. We find similar results in a robustness check that uses a firm-state-year panel with all 29 states available.

\subsection{Hiring/Departing Definitions and Descriptive Statistics}

As one of our main focuses is on the hiring of skilled immigrant workers, it is useful to describe our empirical approach and the nuances imposed by the LEHD's structure in further detail. We define the hiring of a worker as the first time that she is paid a salary by a given firm. We define the departure of an employee as the final time that a person is paid a wage. It is important to emphasize that we do not observe whether a worker's departure was voluntary or whether she was dismissed by the firm. We create these measures over the total employment spell of the worker with the firm. That is, we do not consider an employee not being paid for several quarters by the firm to be a departure and then a re-hiring. We cannot distinguish hiring and departures at the sample end-points and so we drop these years from the analysis when appropriate.

The LEHD's structure allows us to observe workers within the firm across the different states in our sample. We do not consider employee migration across states within the same firm to be a worker departure and re-hiring. As noted, however, we only observe worker-level employment records for firms in 29 states in the LEHD. Thus, we cannot capture these employment changes if the within-firm migration is to or from a non-LEHD state. This is one rationale for requiring that firms have at least $25 \%$ of their employment in the core 18 LEHD states. We obtain similar

\footnotetext{
${ }^{11}$ The LEHD reports wages by quarter, and we define the $\$ 50,000$ threshold using quarterly observations expressed in annualized terms. Periods when the worker is not observed in the LEHD are not used for this calculation. Earnings are deflated to 2008 values using the Bureau of Labor Statistics' All Urban Consumers CPI series. We find similar results to those presented below when using alternative approaches to define skilled workers (e.g., considering initial salaries). Kerr and Lincoln (2010) find little impact of greater inflows of foreign skilled workers on native wages over short time horizons. This suggests that our skill definitions are not likely to be materially influenced by the immigration also being considered.

${ }^{12}$ The LEHD contains an imputed education level for each worker, based on a model using the 1990 Decennial Census long form data. The imputation uses the person's age, state of residence, industry and earnings to come up with a probable level of education. As these traits are some of the key variables in our analysis, using the imputation would not be prudent. The Census Bureau also warns against placing too much confidence in the imputed education level available in the current vintage file (LEHD 2008) and does not recommend its use for research. Nonetheless, similar patterns to our results below are evident when defining skilled workers as those with a bachelor's degree.
} 
results when using higher thresholds, and our main reason for a lower cutoff is to have a greater level of identifying variation. ${ }^{13}$

When analyzing hiring and departing, we decompose employment changes for a firm as consisting of (i) hires in continuing firm-states, (ii) departures in continuing firm-states, and (iii) employment changes due to firms entering or leaving states completely. The first two components are our central focus. The third component is mostly outside of the scope of our approach, and unreported tests find these changes mostly uncorrelated with our variables of interest.

Table 1 provides descriptive statistics on our main sample. The data contain 319 firms in total and 129 in our subsample of top patenting firms. These companies average about 22,000 employees in the 18 core LEHD states, with an underlying range of less than 200 employees to several hundred thousand. Within these firms, $50 \%$ of the workforce is classified as skilled by achieving a median annual earnings of $\$ 50,000$ or more during 1995-2008. The underlying range for this share is less than $10 \%$ to greater than $90 \%$. Of the skilled group, older natives account for about $50 \%$, younger natives for $31 \%$, older immigrants for $9 \%$, and younger immigrants for $10 \%$. Annual rates of skilled worker hiring and departing are $13 \%$ and $14 \%$, respectively. ${ }^{14}$

\subsection{CPS-LEHD Match Occupations}

The LEHD generally does not contain worker occupations, which would be a valuable input for our study. We can, however, make some progress with a special match that has been made by the Census Bureau between the 1986-1997 Current Population Surveys and the LEHD. The CPS is a random sample of individuals, and our firms employ 25,765 CPS workers that have median annualized earnings during the $1995-2008$ period of $\$ 20,000$ or more. In total, these employees comprise 132,507 person-year observations during our sample period. While we do not observe time-varying information on these workers, we utilize below the person's primary occupation at the time of the CPS survey response to identify those who were connected to STEM occupations. In our main employment analyses, we use this STEM variable as one approach to measuring a firm's dependency on skilled immigrants. In a later analysis, we consider differences across occupations in a firm for departure rates. The mean age of these workers at the time of the LEHD observation is 43 , and $9.3 \%$ of them were connected to STEM occupations when the CPS survey was conducted.

\footnotetext{
${ }^{13}$ Using the available data, we find the rate of cross-state mobility within a firm to be very low at $0.3 \%$. This rate uses all 29 LEHD states and is inclusive of M\&A activity. The intrastate mobility rate within a firm is higher, although this rate is more difficult to interpret since it is driven to a higher degree by M\&A activity (i.e., if a merger changes the SEIN of individuals, this is counted as a move for this purpose). For large states, the rate tends to be between $5 \%$ and $7 \%$ for the firms in our sample. For small states, the rate tends to be less than $3 \%$.

${ }^{14}$ The correlations of LBD employment levels to young skilled immigrant and total skilled immigrant shares are -0.24 and -0.25 , respectively, reflective of the smaller patenting firms in the sample that depend more on skilled immigrants. The correlations of LBD employment levels to the total older worker and native older worker shares are 0.14 and 0.12 , respectively. The first two correlations are statistically significant, while the latter two correlations are not.
} 


\section{Firm-Level OLS Employment Analysis}

This section describes our estimating framework and presents our OLS results. These estimations provide a benchmark for our IV results in Section 5 .

\subsection{Estimation Framework for Employment Analysis}

As our paper provides a first empirical depiction of skilled immigration and the employment structures of U.S. firms, we choose a simple estimating equation, outlined below, for the bulk of our analysis. This estimating framework quantifies how expansions in young skilled immigrant employment by a firm are associated with employment changes for other worker groups in the firm. This empirical approach describes the data in a transparent way and is a straightforward extension of the conceptual framework laid out in Section 2. Our choice of this framework is also motivated by the many popular discussions and policy questions about the employment effects of these immigrants. As described in the introduction, these statements are often about how many workers are hired or departing as a firm takes on a new immigrant. These estimations are informative for these statements as well.

Our general approach takes the form

$$
Y_{f, t}=\beta \cdot \ln \left(E m p_{f, t}^{Y S I}\right)+\nu \cdot X_{f, t}+\phi_{f}+\eta_{i, t}+\epsilon_{f, t},
$$

where $\ln \left(E m p_{f, t}^{Y S I}\right)$ is the $\log$ number of young skilled immigrants (denoted with superscript $Y S I$ ) employed in year $t$ by firm $f . Y_{f, t}$ is the outcome variable of interest, and $X_{f, t}$ is a vector of firm-year controls described shortly. We include a vector of firm fixed effects $\phi_{f}$ that control for permanent differences across firms. We also control for sector-year fixed effects $\eta_{i, t}$, where the sector $i$ for each firm is defined as the industry in which the firm employs the most workers in the initial period. We define sectors as manufacturing; wholesale and retail trade; finance, insurance, real estate, and services; and other. As firms span multiple industries, we also include an interaction of linear time trends with the firm's initial share of employment in the first three sector groups as a control variable. We further include an interaction term of a linear time trend with the firm's initial technology intensity measured as patents per skilled worker. When calculating initial values for firms, we use the first three years that the firm is observed in the sample.

Our estimations first-difference the above equation,

$$
\Delta Y_{f, t}=\beta \cdot \Delta \ln \left(E m p_{f, t}^{Y S I}\right)+\nu \cdot \Delta X_{f, t}+\eta_{i, t}+\xi_{f, t}
$$

with the covariates in the $X_{f, t}$ appropriately adjusted and where $\xi_{f, t}=\epsilon_{f, t}-\epsilon_{f, t-1} \cdot{ }^{15}$ Our

\footnotetext{
${ }^{15}$ The efficiency of this first-differences form versus the levels specification turns on whether the error term $\epsilon_{c i t}$ is autoregressive. If autoregressive deviations are substantial, the first-differences form is preferred; a unit-root error is fully corrected. If there is no serial correlation, however, first differencing introduces a moving-average error component. Estimations of the autoregressive parameter in the levels specification for this study find serial correlations of 0.75 , while 0.22 is evident in the first-differenced form.
} 
baseline regressions contain 3,374 observations, cluster standard errors at the level of the firm, and are weighted by the log of the initial young skilled immigrant employment in the firm. The regression weights in our baseline estimations provide a greater sense of the average treatment effect and emphasize better-measured data. They also implicitly give more weight to firms that have a greater share of their employment in covered LEHD states. They sit conceptually inbetween unweighted estimations and those that use raw employment counts as weights, and we obtain similar results using alternative weighting approaches.

The vector of controls includes several basic components beyond the sector-year fixed effects noted earlier. Following the influential work of Card (2001) and related papers, we include several measures related to the general employment conditions of the local area in which the company operates. Firms often have multiple facilities, and they may shift activity across locations depending upon conditions. We thus calculate these controls through weighted averages using the employment distribution of the initial counties in which the firm is operating at the start of the sample period. These weights are kept constant for each firm over time. Our local area controls include log LEHD employment, the log immigrant share, and the log share of workers who are over the age of 40 . This approach forms a set of geographic controls for firm activity.

Second, we include two additional measures related to the supply-push framework developed by Card (2001). We start by calculating each firm's initial skilled immigrant distribution across 12 basic groups based on ethnic and geographic lines. We then calculate each firm's initial skilled immigrant distribution across these different groups. We further calculate the growth in each group relative to 1995 among skilled workers across LEHD states. The supply-push factor then sums across these groups, interacting the initial distributions of workers in the firm with the growth of skilled immigrants at the national level by group. We use an identical procedure to construct a supply-push factor directed at lower-skilled immigration based upon the initial composition of the firm's lower-skilled workers and their national trends. These measures help control for the well-documented clustering of employees of the same ethnicity and country of origin in the workplace. ${ }^{16}$

Third, following the influential work of Borjas (2003) and related papers, we construct a measure that reflects the potential impact of national immigration trends by workers of different ages and education levels. We use the LEHD's education estimates for this work. We build six age-education cells that consider our young and old age groups along with three education levels (i.e., high school diploma or less, some college, and college degree). We then calculate the firm's

\footnotetext{
${ }^{16} \mathrm{Six}$ of these groups are within Asia and include Greater China, South Asia (i.e., India, Pakistan, and Bangladesh), Japan, Vietnam, Korea, and other Asian countries. We specifically separate some of these countries due to their importance to U.S. skilled immigration (e.g., the H-1B program draws about $40 \%$ of its workers from India). Five groups of broader geographic definition include Europe, the Middle East, countries of the former Soviet Union, Latin America, and Africa. We also have a group of dispersed countries of Anglo-Saxon heritage (e.g., Canada, United Kingdom, Australia) and a residual group. The residual group is not included in the supply-push calculations. For evidence of clustering of employees by ethnicity and country of origin see, for example, Mandorff (2007), Andersson et al. (2009, 2012), and Åslund et al. (2012).
} 
initial skilled employment distribution across these six cells. We also calculate for each cell the national growth in skilled immigration compared to 1995 using the public CPS files. Interacting each firm's initial distribution with the national growth by cell, our age-education immigration measure sums over these six groups.

Beyond these baseline controls, we also consider specifications that control for the underlying growth process of the firm by using the employment changes observed for medium-skilled workers. These workers are defined to be those with median salaries of $\$ 25,000-\$ 50,000$ across the sample period; this group is mutually exclusive from the skilled worker group. When using this control, we naturally sacrifice our ability to study how immigration employment relates to overall firm size, instead shifting attention to effects among skilled worker groups. On the other hand, we gain several benefits. For OLS estimations, the key benefit is having greater robustness to corporate restructuring events or dramatic changes in firm size not linked to immigration. We discuss in the next section even larger benefits for the IV estimations from this control.

\subsection{OLS Employment Estimations}

Table 2 provides our baseline OLS results using specification (5), where column headers indicate the outcome variables $Y_{f, t}$ considered by each specification. The title of each panel describes the sample employed and the included controls $X_{f, t}$. Column 1 of Panel A quantifies the correlation between the change in log employment of older native skilled workers and the change in log employment of young skilled immigrants in the firm without covariates. The $\beta$ coefficient is well measured and can be interpreted as a $10 \%$ increase in skilled immigrant employment for the firm correlating with a $6 \%$ increase in the employment of older skilled natives. Column 2 finds a similar expansion of $7 \%$ for young skilled native workers. Column 3 displays a slightly larger increase for older skilled immigrant workers, and Column 4 finds the overall elasticity of skilled worker employment in the firm to be 0.64 .

The next three columns of Table 2 document changes in some simple employment traits of the firm's skilled workforce. Across the sample in Panel A, a $10 \%$ increase in young skilled immigrant employment for the firm corresponds with a $0.3 \%$ increase in the share of skilled workers who are immigrants. The share of skilled workers in the firm who are over the age of 40 also declines by $0.3 \%$. This older worker share decline is not solely due to the mechanical effect of employing more young skilled immigrants, as Column 7 shows a $0.2 \%$ decline among native workers only. A similar test shows that a $10 \%$ increase in the young skilled immigrant workforce lowers the average age of the firm's skilled workforce by $0.1 \%$.

Columns 8 and 9 analyze the overall U.S. employment of the firm in LEHD states and the skilled immigrant share. A $10 \%$ increase in skilled immigrant employment for the firm correlates with a $6 \%$ increase in total firm employment. A similar elasticity is evident for lower-skilled workers by themselves. Given the comparability of these elasticities, the final column shows 
only a slight increase in the skilled worker share of the firm. ${ }^{17}$

Panel B then adds the basic controls to the estimation framework, which do not materially influence the estimated elasticities from Panel A. Panel C further adds the log change in the firm's medium-skilled workforce, which has a larger substantive effect on the coefficient estimates. The overall employment elasticity in Column 4 declines to 0.47 . Thus, a $10 \%$ increase in the young skilled immigrant workforce of the firm correlates with a $5 \%$ increase in the total skilled workforce of the firm. Looking at Columns 1-3, this expansion tends to favor young natives and older immigrants compared to older natives. Accordingly, Columns 4-7 show stronger shifts in the immigrant and older worker shares of the firm. Finally, Panel D finds similar effects when looking at the subsample of top patenting firms.

\subsection{OLS Hiring and Departing Estimations}

Tables $3 \mathrm{a}$ and $3 \mathrm{~b}$ next consider the hiring and departing of various worker groups contemporaneous with the hiring of young skilled immigrants. We continue to use specification (5), with the key regressor being $\Delta \ln \left(H_{i r i n g}^{Y S I}\right)$. Thus, we are quantifying how changes in the rate at which firms hire young skilled immigrants are associated with changes in the hiring or departing rates of other groups. The hiring of skilled immigrants in this analysis is not restricted to new arrivals, but includes any immigrant regardless of how long they have been working in United States. The Panels A-D are defined as in Table 2.

Columns 1-4 consider as outcomes the log hiring of different groups. Elasticities on this margin are similar to those measured for the total change in the workforce in Table 2. In Panel $\mathrm{C}$, a $10 \%$ increase in young skilled immigrant hiring is associated with a 5\%-6\% increase in older and younger native hiring. We generally find similar results when including additional controls or restricting the sample to the top patenting firms. Columns 5-8 consider as outcomes the log departing rates of groups. Panels $\mathrm{A}$ and $\mathrm{B}$ find no material changes in leaving rates associated with increased young skilled immigrant hiring. Panels $\mathrm{C}$ and D incorporate the medium-skilled worker control and find a decline in departing rates for skilled workers when young skilled immigration hiring increases.

Table $3 \mathrm{~b}$ then relates these hiring changes to shifts in the overall composition of the firm's skilled workforce, similar to Table 2 . The coefficient estimates are substantially lower here than in Table 2 due to our focus just on changes in the hiring dimension rather than net changes in overall employment. The specification in Panel $\mathrm{C}$ suggests that a $10 \%$ increase in the hiring of

\footnotetext{
${ }^{17}$ One thing to note with respect to our results in Columns 4-6 and 8-9 is that the employment of young skilled immigrants is naturally a component of the dependent variable in each specification. We report these outcomes as their magnitudes are informative and non-obvious. For example, the expanding employment of young skilled immigrants clearly plays a direct role in the positive increase in the immigrant share of skilled workers in Column 5. This share is nevertheless an important summary statistic and the overall response could even have been negative if the expanding employment of young skilled immigrants is associated with large increases in native employment (e.g., the claims made about hiring alongside the H-1B program noted in the Introduction). The econometric issues with having the young skilled immigrants as component of the dependent variable should be kept in mind when viewing these results.
} 
young skilled immigrants increases the total skilled workforce of the firm by about $0.5 \%$. Growth is strongest in the immigrant worker group documented in Column 4, but it is also present for other groups of workers as well. Growth is again weakest among older natives. ${ }^{18}$

We have repeated this analysis without the log transformation of variables. While the non-log approach introduces scale effects, it is useful to consider them given that the claims of advocacy groups are often expressed in raw counts. The hiring of one young skilled immigrant worker is associated with a total employment expansion of 4.5 workers. This includes about 1.4 older native workers, 1.7 younger native workers, and 0.4 older immigrant workers. It also includes the net addition of a little less than one young skilled immigrant worker after accounting for departures. More importantly, the overall depiction of the results is quite similar to the approach using logs. The lower elasticity of older natives in the log format in part reflects the larger base of older natives in the workforce.

\subsection{OLS Robustness Analysis}

The OLS estimation results overall speak to increased hiring and employment of natives when the young skilled immigrant workforce of a firm expands. These results are robust to a number of different approaches. To mention a few important ones, we first find similar results using a firm-state approach that allows us to include all 29 states. The elasticity estimates are somewhat lower with this approach than in the firm panel, which may indicate that the firm as a whole operates differently compared to individual units (e.g., shifting production across facilities). We also find similar results when raising the inclusion threshold to $66 \%$ employment in LEHD states, when splitting the sample by the long-term growth rates of the firms, when setting minimum employment thresholds for companies, when using different weighting strategies, and when using the alternative definitions of skilled workers noted in the previous section.

\section{$5 \quad$ Firm-Level IV Employment Analysis}

The OLS patterns documented in Section 4 are striking and novel to observe. There are, however, two clear concerns. The first is that the hiring of young skilled immigrants is likely to be influenced by other factors impacting the firm. The resulting biases could be upwards or downwards in direction. For example, an upward bias might result from the firm having a new product that it wants to launch, where the firm hires both natives and young skilled immigrants to pursue the opportunity. Likewise, large-scale employment declines for a shrinking firm can hit all groups at once and induce a correlation. On the other hand, a downward bias could emerge to the extent that young skilled immigrants are being recruited to provide staffing in difficult hiring situations. This latter scenario, in fact, is one of the original intentions of the H-1B visa

\footnotetext{
${ }^{18}$ These patterns look very similar when also considering "new arrival" immigrant hiring as the explanatory variable, where new arrival is defined to be the first time the immigrant is observed in the LEHD dataset.
} 
program, and multiple studies have documented the role of immigrants in these situations (e.g., Borjas 2001, Kerr 2010, Ruiz et al. 2012).

The second concern is more mundane but also important. While building from the microdata, our right-hand-side variables are measured with error. First, we will have some degree of classical measurement error due to inaccurate reporting (e.g., an individual's place of birth is inaccurately transcribed). This measurement error downward biases coefficient estimates towards zero. Second, there are corporate mergers and acquisitions that we have not been able to account for with our composite firms. This type of issue will bias our estimates upwards to a degree that depends upon how similar the employment distribution of the joining firm is to the base firm. As one specific example, if the employment structure of an acquired firm is an exact match to the base firm employment structure, the bias would be towards one. ${ }^{19}$ This section develops and presents IV estimations to address these concerns.

\subsection{Design}

Before describing the specifics of our IV design, it is helpful to start with a discussion of what using the instruments is attempting to accomplish. We begin by considering our control variable, the supply-push immigration factor for skilled workers. Recall that this measure interacts the initial place-of-birth distribution of a firm's skilled workers with aggregate changes in skilled immigration from various countries across LEHD states. This factor is a strong predictor of increased young skilled immigrant employment in the firm, and one potential approach would have been to use this supply-push factor as an instrument. In doing so, we would encounter two potential concerns to address. The first would be whether the initial distribution of country groups for skilled immigrants used in the interaction is correlated with something else that affects the measured outcomes. The second concern for this type of instrument is whether the national trends used for immigration groups are endogenous to the needs or opportunities of the firms that employed them. For example, immigration flows from Japan to the United States might increase when firms that rely heavily on skilled Japanese workers have better opportunities. Thus, even though we would instrument for the direct hiring of the firm, the instrument's reliance on the national trends might not be a complete solution.

A stronger IV approach would instead consider mandated rates of immigration to the United States by country. U.S. immigration policy does not generally contain such country-specific controls on immigration, but it does provide some empirical footholds through the H-1B program.

\footnotetext{
${ }^{19}$ It is impossible to calculate exactly the typical employment ratio of an acquired firm. First, in large part, these acquisitions are not observed. Second, and more conceptually, it can be difficult to distinguish precisely which firm is the true acquirer (e.g., mergers among equals). We can make some headway on this issue, however, by comparing the descriptive statistics of the firms in our sample that have undergone significant M\&A to the sample as a whole. The M\&A group has a very similar average size to the full sample. The most noticeable difference is that their workforces tend to be more skilled than the full sample. Within the skilled workforce group, these major M\&A firms are slightly tilted towards a greater immigrant share, but the age and citizenship profiles are otherwise quite balanced. As a whole, this suggests that biases due to un-modeled M\&A will be in the neighborhood of unit elasticity when considering our primary outcomes focused on the composition of the skilled workforce.
} 
We next describe the $\mathrm{H}-1 \mathrm{~B}$ program in greater detail and the instruments that we have developed based on changes in this program. The construction of our instruments is conceptually similar to the supply-push framework just discussed. We will seek, however, to use the program's legal structure to deal with some of the concerns that would have existed for a traditional supply-push framework (which still serves as a control variable).

The H-1B is a temporary immigration visa that allows U.S. employers to seek short-term help from skilled foreigners in "specialty occupations." These occupations are defined as those requiring theoretical and practical application of specialized knowledge like engineering or accounting; virtually all successful H-1B applicants have a bachelor's education or higher. The visa is used especially for STEM occupations, which account for roughly $60 \%$ of successful applications. The worker can come from anywhere in the world, and the application specifies the local area in which the employee will work in the United States. Approximately $40 \%$ and $10 \%$ of H-1B recipients over 2000-2005 came from India and China, respectively. Shares for other individual countries are less than $5 \%$.

Since the Immigration Act of 1990, there has been an annual cap on the number of H-1B visas that can be issued. The cap governs new H-1B visa issuances only; renewals for the second three-year term are exempt, and so the maximum length of stay on an H-1B is effectively six years. While most aspects of the program have remained constant since its inception, the cap has fluctuated significantly. Figure 2 uses fiscal year data from the USCIS to plot the evolution of the numerical cap. The 65,000 cap was not binding in the early 1990s but became so by the middle of the decade. Legislation in 1998 and 2000 sharply increased this limit over the next five years to 195,000 visas. These short-term increases were then allowed to expire in 2004, when visa demand fell short of the cap. The numerical limit returned to the 65,000 level and became binding again, despite being subsequently raised by 20,000 through an "advanced degree" exemption. ${ }^{20}$

While the level of the cap is published by the USCIS, H-1B entry rates and population stocks are not definitively known. Lowell (2000) builds a demographic model for this purpose that factors in new admissions and depletions of the existing $\mathrm{H}-1 \mathrm{~B}$ pool by transitions to permanent residency, emigration, or death. While $\mathrm{H}-1 \mathrm{~B}$ inflows are reasonably well measured, constructing the latter outflow estimates requires combining available statistics with modelling assumptions. In Lowell's model, emigration and adjustment to permanent residency are roughly comparable in magnitude, with the time spent from entry to either event being estimated through typical H-1B experiences. Figure 2 shows updated estimates provided to us by Lowell. The H-1B population grew rapidly in the late 1990s before leveling off after 2000. The lack of growth immediately after this point can be traced to weak U.S. employment opportunities during this period. When demand returned, however, the reduced supply of $\mathrm{H}-1 \mathrm{~B}$ visas restricted further growth.

\footnotetext{
${ }^{20}$ Kerr and Lincoln (2010) provide a more extended discussion of the program and its history. This study also discusses the two temporary work visas that are the most similar to the H-1B, the L-1 and TN visas. These programs show limited substitutability with the H-1B visa. See also Lowell and Christian (2000).
} 
These shifts in the size of the H-1B program, driven in large part by legislative changes, provide an attractive alternative to using national immigration trends by country. We thus construct instruments that are similar in spirit to the supply-push approach but that are more exogenous. The basic approach for the construction of each of these instruments is to first measure a fixed dependency for the firm on the H-1B program. We then interact this dependency with the log change in the program's size to define an instrument for the log change in young skilled immigrant employment in the firm.

We measure the fixed dependency of the firm in three ways. Our first measure is the log ratio of the firm's Labor Condition Applications (LCAs) to its skilled employment in 2001. To obtain an H-1B visa, an employer must first file an LCA with the U.S. Department of Labor (DOL). The primary purpose of the LCA is to demonstrate that the worker in question will be employed in accordance with U.S. law. The second step in the application process after the LCA is approved is to file a petition with the USCIS, which makes the ultimate determination about the visa application. The DOL releases micro-records on all applications that it receives, numbering 1.8 million for 2001-2006. These records include firm names and proposed work locations. We use these records to describe firm dependencies (in the 18 core LEHD states) from the earliest year that is available (2001). It is important to note that this measure does not indicate granted visas but instead the demand that firms have for the visas. One drawback of this measure, however, is that it is measured in the middle of our sample period.

We complement this LCA-based measure with two other indicators of a firm's sensitivity to changes in the H-1B visa program. Given the program's heavy reliance on Chinese and Indian immigrants, our second measure uses the LEHD records to define the firm's initial share of skilled immigrant workers that were born in these countries. Likewise, as the program is particularly important for STEM occupations, we define our third measure as the share of the firm's workforce in STEM occupations using the LEHD-CPS match. We measure this in the first three years where matched employees are observed, which may be later than the typical initial period. Given the limited LEHD-CPS match counts for some firms, this metric has higher measurement error than the other two approaches. These raw measures are quite skewed, and so we winsorize these shares at their $5 \%$ and $95 \%$ values. The pairwise correlation of the three measures is 0.59 between the LCA-based measure and the initial Chinese and Indian share, 0.45 between the LCA-based measure and the initial STEM share, and 0.59 between the initial Chinese and Indian share and the initial STEM share.

We then interact these three measures, in turn, with a measure of the H-1B program's size. Our primary measure of program size is Lowell's set of H-1B population estimates, expressed in logs. The Lowell estimates have the advantage that they reflect the population's true development and experienced growth that was predominantly governed by a mandated cap. They have the disadvantage that they may retain some endogeneity given the slow growth in the program's size during the high-tech recession when demand fell well short of the cap. As a result, in robust- 
ness checks we consider a second measure of the log of the summation of the previous six years' numerical visa caps. The time frame is chosen due to the fact that the $\mathrm{H}-1 \mathrm{~B}$ visa is effectively of a length of six years, inclusive of visa renewal. The advantage of this measure is that it is more exogenous. There is a key period in the early 2000s, however, when H-1B demand declined substantially at the same time that the cap was still high, and thus the six-year summation is not as reflective of the program's size. We describe further below the limitations of using cap summations.

The exogeneity of the instruments requires that the initial shares used in their construction be uncorrelated with the error term. The natural worry would be that a measure like the initial Chinese and Indian share is associated with some other firm trait besides H-1B usage that affects employment outcomes during the period of study. The most plausible candidates would include a firm's innovation intensity or its economic sector, and so we must assert that the existing covariates are sufficient in this regard. Likewise, we rely on our "supply push" controls to account for ethnic hiring networks outside of the visa changes. We will further test below including an interaction of the initial traits with time trends, in order to require that the identification come off the non-linear movements of the $\mathrm{H}-1 \mathrm{~B}$ trend. This will help provide comfort against slow-moving, linear omitted factors that could be correlated with the initial shares.

Finally, it is worth noting that our sample contains a large proportion of the United States' $\mathrm{H}-1 \mathrm{~B}$ workers and that these workers also represent a large portion of the young skilled immigrant group within these firms. We do not know either of these shares precisely, but we can make some rough calculations. Within the 18 LEHD states, our final sample contains about 16,400 LCAs in 2001, out of a raw sample of 127,000. After removing non-U.S. companies, universities and public-sector institutions, and similar users of H-1B visas, we estimate that about $15 \%-20 \%$ of LCAs are included in our firm group, representing a substantial share of the program. In 2001, the vast majority (86\%) of firms in our sample filed for an LCA, and the average number of applications for those firms found in the LCA data was $97 .{ }^{21}$ For the second figure, the $0.8 \%$ LCA dependency average in Table 1 represents one year of applications made by our firms. We multiply this share by five to represent the six-year nature of the program but also the fact that 2001 was a high year for H-1B visas. Dividing this figure by the $9.5 \%$ average share for young skilled immigrants in Table 1 suggests that about $42 \%$ of the young skilled immigrant workers in these firms are $\mathrm{H}-1 \mathrm{~B}$ holders. A broader calculation of $35 \%$ is derived by comparing Lowell's estimate of 501,000 H-1B workers in 2001 to the CPS estimate of 1.4 million non-citizen immigrants with bachelor's educations in the same year. These estimates do not count past H-1B holders who have transitioned to permanent residency.

\footnotetext{
${ }^{21}$ As a side note, LCA usage is comparable in the firms that we excluded when building the final sample. For example, $77 \%$ of excluded companies file an LCA, compared to $86 \%$ in the final sample. Included firms file $1.9 \mathrm{x}$ as many LCAs as excluded firms, but they are also 1.8x larger on average.
} 


\subsection{Estimations}

Tables 4-7 report our IV results. Standard errors are clustered by firm across our different specifications. Table 4 begins with IV estimations that do not contain the medium-skilled workforce control. The order of columns in Table 4 mirrors that in Table 2. Panel A presents results that use the LCA-based dependency measure, Panel B considers estimations that use the initial Chinese/Indian share of skilled workers, and Panel C presents results that use the initial STEM worker shares. Each of these dependencies is interacted with the Lowell population estimate for the national size of the program. The fit of the first stage estimations, indicated beneath each panel, pass standard criteria in Panels A and B. The first stage in Panel C is weak. Generally, across our IV estimations, the first stages tend to be weaker for the occupation-based measure, which is not surprising given measurement error from the CPS sample noted above.

The second-stage estimations resemble and differ from the OLS estimates in meaningful ways. The first four columns again consider changes in employment levels of skilled groups. The IV estimations generally suggest in Column 4 that the skilled workforce of the firms grows with expansions in immigrant employment, although Panel A finds no response. On the other hand, looking at Columns 1-3, IV estimations agree that young native employment expands with the hiring of young skilled immigrants. The ambiguity for the total workforce comes from differences across the IV estimations in whether the older skilled native workforce expands. In Panel A, a decline is evident, while in Panels B and C increases are evident. Even in the latter two cases, coefficient estimates tend to be significantly smaller for older skilled natives than for younger skilled natives.

With this background, it is not surprising that the strongest points of similarity are on the ratios provided in Columns 5-7 of Table 4. IV estimations consistently find that the immigrant share rises and the older worker share falls with expansions in skilled immigrant employment in the firm. On this dimension, the IV estimations are larger in magnitude than the OLS specifications. Thus, the IV specifications suggest that OLS estimations understate the extent to which the employment structure of the firm shifts to favor immigrants and younger workers when the young skilled immigrant group expands. In the last two columns, we consider firm size and skilled worker shares. Table 4's IV estimations do not confirm the growth in total firm size observed in the OLS estimations, but the increase in the skilled worker share is again observed. The qualifications noted earlier for specifications where the employment of young skilled immigrants is a component of the dependent variable holds in these IV results.

Unfortunately, we are unable to make further progress with this unstructured approach. We are not able, for example, to substitute in the cap summation for the Lowell population trend as doing so delivers an insufficient first-stage fit. Moreover, these estimates are sensitive to various reasonable adjustments like removing sample weights. The underlying challenge is straightforward. We are attempting with the IV to predict the year-by-year changes in young skilled immigrant hiring for firms across the 1995-2008 period. With such a long time period, 
there are many other forces that impact these firms, weakening our first-stage fit. The cap summation approach is also very difficult here given the behavior of the H-1B cap during the high-tech recession.

To gain further traction, we introduce additional structure on the firm growth process in Table 5 by controlling for the contemporaneous changes in medium-skilled worker employment in the firm. By doing so, we sacrifice the ability to estimate changes in total firm size, but we are able to consider changes among skilled workers. Table 5 generally agrees with Table 4 . It continues to be true that expansions in young skilled employment in firms connect to a higher immigrant share of skilled workers and a younger age structure. With this framework, we find more substantial agreement across the IV estimations that the total skilled workforce size grows.

This empirical specification in Table 5 provides substantially more traction, and the next two tables extend this work. Table 6 considers an alternative instrument that uses the log of the summation of the previous six years' numerical visa caps as a measure of H-1B program size. As mentioned above, this measure has the benefit that it is likely more exogenous but has the liability that it is not as reflective of the program's true size. Results here are generally similar to those in the preceding two tables but tend to be somewhat sharper in terms of statistical significance. In particular, we find consistent evidence of larger responses amongst young natives to young skilled immigrant employment expansions relative to older natives. Estimations also find significant increases in the total skilled workforce in response to greater employment of young skilled immigrants. We consider instruments separately as joint estimation fails overidentification tests in the first stage.

Tables $7 \mathrm{a}$ and $7 \mathrm{~b}$ provide some further robustness checks on Tables 5 and 6 , respectively. Panel A shows similar results using the sample of major patenting firms. Panel B finds similar results with unweighted specifications. Panel $\mathrm{C}$ includes an additional control for the fixed LCAbased dependency in the first-differenced regression, equivalent to a linear time trend interacted with the dependency in a levels regression. The same patterns are again evident with this control, with the results even more accentuated. This robustness holds true when alternatively considering our other interaction measures. Panel D reports similar results using a balanced panel of firms present across the full sample period. Finally, Panel E shows similar results when dropping firms that lobby about immigration issues (Kerr et al., 2013). ${ }^{22,23}$

On the other hand, it is important to note two limitations of these IV analyses. We have

\footnotetext{
${ }^{22}$ Unreported estimations split the sample into firms primarily engaged in manufacturing, trade, or services/other. These demarcations roughly split the sample into equal-sized bins. Disclosure restrictions prevent us from showing these results separately by industry group, but we can report that overall these groups behave fairly similarly. All three groups show an instrumented elasticity for log total skilled employment between 0.2 and 0.6 from young skilled immigrant employment growth, compared to the full sample's 0.4 elasticity. Each group further displays a coefficient for the immigrant share analysis between 0.07 and 0.10 , compared to the full sample's overall coefficient of 0.075 . Likewise, declines in total older worker and native older worker shares with higher young skilled immigrant hiring are present and economically important in all three categories, ranging from -0.07 to -0.26 , compared to the full sample's coefficient of -0.149 . The age profile shifts are smallest in manufacturing.

${ }^{23}$ The results are robust to dropping the major M\&A firms. The ratios are almost identical to those reported for the full sample, and the employment size responses grow by about $10 \%$.
} 
tested various approaches that adjust the dates of the major $\mathrm{H}-1 \mathrm{~B}$ changes by a couple of years forward or back from the true reforms. When doing so, the patterns are mixed. We often find contemporaneous effects to be the most important, but the patterns are unfortunately too sensitive to draw conclusions. Likewise, while our results are robust to dropping a few years at the beginning or end of the sample period, they are not robust to major changes in sample duration (e.g., dropping years prior to 2002) due to the much smaller sample size and reduced variation in the $\mathrm{H}-1 \mathrm{~B}$ population changes.

\section{Occupation-Level Estimations}

This section considers how employment effects might differ across workers by occupation within a firm. In particular, we focus on whether older workers in STEM occupations are more vulnerable to displacement effects from young skilled immigration. We first undertake some calculations on the age elasticities of substitution for skilled workers by occupation to provide a more systematic foundation for understanding why this might be case. We then study departure patterns by occupation in our data using the CPS-LEHD matched sample.

\subsection{Occupation-Level Elasticities of Substitution by Age}

Starting with Borjas (2003), a number of studies within the immigration literature consider estimating elasticities of substitution using a CES production function. Skipping some of the theoretical background that is provided, for example, by Borjas et al. (2012), we similarly focus on estimating the elasticity of substitution between worker groups along a specified dimension. For our purposes this estimation takes the form

$$
\ln \left(\text { Wage }_{a, t}\right)=\gamma \cdot \ln \left(\operatorname{Emp}_{a, t}\right)+\phi_{a}+\eta_{t}+\epsilon_{a, t}
$$

where $a$ indicates worker age groups and $t$ indicates time. This estimation is intuitively a panel analysis of how the employment of an age group correlates with the earnings of workers in that age group. If there is very little substitution across age groups, the increase in employment of workers in one age category relative to the other groups should depress the wages of the workers in that group (a negative $\gamma$ coefficient). On the other hand, if substitution across the groups is very easy, then the increased employment of one group should not influence that group's relative wage significantly (a $\gamma$ coefficient of zero). This measure can also be expressed as the elasticity of substitution $-1 / \gamma$, with larger elasticities indicating greater levels of substitution.

The specification is estimated at the occupational level using workers with bachelor's degrees or higher in the CPS from 1995-2008. We consider workers aged 20-59 and define our four age categories as 20-29, 30-39, 40-49, and 50-59. We further group the CPS's base occupations into larger groups to provide a sufficient level of identifying variance and more meaningful comparisons. The elasticities with respect to age are substantially higher in the STEM-related fields 
than among other workers. STEM fields account for three of the four highest elasticities that we estimate (elasticity and standard error): computer-related occupations at 27.4 (19.7), engineers at 14.6 (8.3), social workers at 8.6 (4.8), and scientists at 7.4 (3.5). Management-related occupations are next at 7.0 (1.6), and many occupations have elasticities between five and seven, including lawyers, accountants, administrators, and doctors. Some occupations like teachers have elasticities of substitution close to zero.

Higher elasticities of substitution by age for STEM occupations give one indication as to why older natives may experience displacement from young skilled immigration. In terms of the recent nested models emphasized by Ottaviano and Peri (2012), the argument surrounding STEM substitution can be essentially thought of as a four-level system with the order of education, occupation, age, and then immigration status. We are focusing on workers with at least a bachelor's education, and we allow for different elasticities over ages by occupation. Finding a very high elasticity of substitution by age in an occupation suggests that immigrants in one age group of the occupation can substitute equally as well for natives in other age groups as they can for natives in their own age group.

Some visual evidence for this effect can be seen in a descriptive exercise using the CPS. Figure 3 plots immigration and age profiles in computer occupations in the top five $\mathrm{H}-1 \mathrm{~B}$ dependent states relative to the rest of the United States. We focus on computer occupations given the high elasticities just identified. We plot three series: (i) the relative rate of immigration employment in computer-related occupations in the top five H-1B states to other states; (ii) the relative rate of older worker employment in computer-related occupations in top five H-1B states to other states; and (iii) the relative rate of older worker employment in all occupations in top five $\mathrm{H}-1 \mathrm{~B}$ states to other states. As can be seen in the figure, the second series varies inversely with the first series, while the third series is relatively flat. This is true both with respect to the expansion of the $\mathrm{H}-1 \mathrm{~B}$ visa program as well as when the legislation behind this expansion expired and the program reverted back to its original size in $2004 .{ }^{24}$

\subsection{Departure Rates by Occupation}

With this background, Table 8 provides some simple estimations of departure rates by occupation within our firms and how they correlate with the hiring of young skilled immigrants. It is worth stressing again that an employee's occupation is observed once during the 1986-1997 period, and we are applying that past trait forward to the 1995-2008 period. Our sample includes U.S.born workers aged 20-65 in the observation year of the LEHD. Included workers have median annualized earnings during the 1995-2008 period of $\$ 20,000$, and our final data set comprises 132,507 person-year observations with 25,765 workers.

To study substitution across different types of workers, we consider a linear probability model

\footnotetext{
${ }^{24}$ Caution should be exercised in considering levels changes between 2002 and 2003 since the CPS was redesigned during this period. See also Brown and Linden (2011) and Wadhwa (2010).
} 
where the outcome variable is an indicator variable for an individual departing from his or her firm. Our analysis here uses OLS and thus should be considered descriptive. The key explanatory variable is the growth in young skilled immigrant employment in the firm by year. To study occupational and age differences in an intuitive way, we interact this immigration regressor with three indicator variables for (i) older worker in STEM occupations, (ii) young worker in STEM occupations, and (iii) older worker in non-STEM occupations. With this approach, the reference category is young workers in non-STEM occupations. We include in all regressions a vector of fixed effects for current worker ages using the bins 20-29, 30-39, 40-49, 50-59, and 60+ years old. Regressions are unweighted and cluster standard errors by firm.

Column 1 of Table 8 reports the base results that include year fixed effects. The first row finds that higher growth of young skilled immigration to the firm is associated with lower departure rates for young natives in non-STEM occupations. These baseline estimates are consistent with the idea that firms on a positive growth trajectory may better retain employees and also recruit new ones. There are, however, substantial differences across worker types. There is no reduction in departure rates for older workers in STEM fields at the time of increased young skilled immigration into the firm, and the departure rate for young natives in STEM fields is only modestly affected. Column 2 finds similar results with an alternative approach where we include firm-year fixed effects. With these fixed effects, we no longer estimate the main effect of young skilled immigrants into the firm, and the coefficients still provide age-occupation comparisons to the omitted category of young native workers in non-STEM occupations. Young skilled immigration is most closely associated with departures of older STEM workers in the firm, although the differences by age across STEM occupations are not statistically significant.

Columns 3 and 4 take a second step of splitting workers based upon salary levels, which are estimated using the LEHD and are allowed to be time varying. We define high-wage workers to be those earning more than $\$ 75,000$ in real 2008 dollars on an annualized basis. This added dimension uncovers several interesting comparison points. Among older STEM workers, the higher departure rates are exclusively in the higher wage group, with the differences by salary levels statistically significant. There is not a comparable pattern for young STEM workers. On the other hand, one observes in the non-STEM occupations directionally similar patterns. The results in Column 4 show that this finding is robust to including age-occupation fixed effects. In this specification, the differences across salary levels for older STEM and non-STEM workers are $0.192(0.093)$ and $0.110(0.032)$, respectively. While the former is larger in magnitude, the base effects for higher earners are not significantly different from each other at $0.102(0.039)$ and 0.086 (0.027), respectively.

We have extended this analysis in several ways. First, Column 5 examines firm-level hiring of these matched workers and does not find this pattern, indicating this is not due to greater churn in the labor market. We find similar results that are sometimes even sharper when using the estimated age elasticities by occupation from the CPS calculated in Section 6.1. We adopt 
Table 8's indicator variable approach for reported results given its intuitive nature. Finally, because the CPS-LEHD match predates our sample period, we cannot use it to describe the immigrants in the firms. We can, however, obtain a glimpse using the occupations listed on the LCA applications the firm makes in 2001. Using the elasticities calculated in Section 6.1, we identify the weighted elasticity of substitution by age across the applications that the firm makes. The differentials estimated across salary levels are almost three times higher for firms whose LCA applications display an average elasticity above the sample median compared to firms below the median. These tests provide some additional verification that the age elasticity of substitution for occupations can have an important moderating effect for how firm employment structures are influenced by young skilled immigration.

\section{Conclusions}

In summary, the results of this study provide a multi-faceted view of the impact of young skilled immigrants on the employment structures of U.S. firms. We find consistent evidence linking the hiring of young skilled immigrants to greater employment of skilled workers by the firm, a greater share of the firm's workforce being skilled, a higher share of skilled workers being immigrants, and a lower share of skilled workers being over the age of 40. Results on whether total firm size increases or not are mixed. There is also consistent evidence in our IV specifications that older native employment expands very little, which is different from the other employment groups. Unlike this lack of growth, however, there is limited evidence connecting actual departures of workers to the hiring of young skilled immigrants. The closest connection is a relative statement across occupations within a firm that suggests that departure rates for older STEM occupations may be higher.

Beyond this specific application, our study makes the larger point that the firm needs to take a much bigger role in immigration work going forward. This approach accounts for a greater level of heterogeneity and makes sense intuitively given that substantial portions of the U.S. immigration framework have been designed to allow U.S. firms to choose the immigrants that they want to hire. Some of the most prominent features of this analysis would have been obscured with standard approaches to immigration's effects. Our results have important implications for the competitiveness of U.S. firms, the job opportunities of natives and immigrants employed by the firms, our larger national innovative capacity (e.g., Furman et al. 2002), and much beyond. This study is a first step towards this characterization, and in current research we are linking these employment changes to changes in patenting levels for firms. We hope that future work continues in this vein. 


\section{References}

[1] Andersson, Fredrik, Monica Garcia-Perez, John Haltiwanger, Kristin McCue, and Seth Sanders, "Workplace Concentration of Immigrants", Working Paper (2009).

[2] Andersson, Fredrik, Simon Burgess, and Julia Lane, "Do as the Neighbors Do: The Impact of Social Networks on Immigrant Employment", Working Paper (2012).

[3] Åslund, Olof, Lena Hensvik, and Oskar Skans, "Seeking Similarity: How Immigrants and Natives Manage in the Labor Market", Working Paper (2012).

[4] Axtell, Robert, "Zipf Distribution of U.S. Firm Sizes", Science 293 (2001), 1818-1820.

[5] Balasubramanian, Natarajan, and Jagadeesh Sivadasan, "What Happens When Firms Patent? New Evidence from US Economic Census Data", Review of Economics and Statistics 93:1 (2011), 126-146.

[6] Barth, Erling, Bernt Bratsberg, and Oddbjørn Raaum, "Immigrant Wage Profiles Within and Between Establishments", Labour Economics 19:4 (2012), 541-556.

[7] Borjas, George, "Economics of Immigration", Journal of Economic Literature 32 (1994), 1667-1717.

[8] Borjas, George, "Does Immigration Grease the Wheels of the Labor Market?", Brookings Papers on Economic Activity 2001:1 (2001), 69-119.

[9] Borjas, George, "The Labor Demand Curve Is Downward Sloping: Reexamining the Impact of Immigration on the Labor Market", The Quarterly Journal of Economics 118:4 (2003), 1335-1374.

[10] Borjas, George, "Do Foreign Students Crowd Out Native Students from Graduate Programs?", in Ehrenberg, Ronald, and Paula Stephan (ed.), Science and the University (Madison, WI: University of Wisconsin Press, 2005).

[11] Borjas, George, "Immigration in High-Skill Labor Markets: The Impact of Foreign Students on the Earnings of Doctorates", NBER Working Paper 12085 (2006).

[12] Borjas, George, and Kirk Doran, "The Collapse of the Soviet Union and the Productivity of American Mathematicians", Quarterly Journal of Economics 127:3 (2012), 1143-1203.

[13] Borjas, George, Jeffrey Grogger, and Gordon Hanson, "Comment: On Estimating the Elasticities of Substitution", Journal of the European Economic Association 10:1 (2012), 198210.

[14] Brown, Clair, and Greg Linden, Chips and Change (Google E-Book, 2011).

[15] Card, David, "The Impact of the Mariel Boatlift on the Miami Labor Market", Industrial and Labor Relations Review 43:2 (1990), 245-257.

[16] Card, David, "Immigrant Inflows, Native Outflows, and the Local Labor Market Impacts of Higher Immigration", Journal of Labor Economics 19:1 (2001), 22-64.

[17] Chellaraj, Gnanaraj, Keith Maskus, and Aaditya Mattoo, "The Contribution of Skilled Immigrations and International Graduate Students to U.S. Innovation", Review of International Economics 16:3 (2008), 444-462. 
[18] Choudhury, Prithwiraj, "Return Migration and Distributed R\&D in Multinationals - A Study Using Micro Data", Working Paper (2012).

[19] Clemens, Michael, "The Roots of Global Wage Gaps: Evidence from Randomized Processing of U.S. Visas", Working Paper (2012).

[20] Cortes, Patricia, "The Effect of Low-Skilled Immigration on US Prices: Evidence from CPI Data", Journal of Political Economy 116:3 (2008), 381-422.

[21] Desai, Mihir, C. Fritz Foley, and James Hines, "Domestic Effects of the Foreign Activities of US Multinationals", American Economic Journal: Economic Policy 1:1 (2009), 181-203.

[22] Dustmann, Christian, Albrecht Glitz, and Tommaso Frattini, "The Labour Market Impact of Immigration", Oxford Review of Economic Policy 24:3 (2008), 477-494.

[23] Facchini, Giovanni, Anna Maria Mayda, and Prachi Mishra, "Do Interest Groups Affect U.S. Immigration Policy?", IMF Working Paper 244 (2008).

[24] Foley, C. Fritz, and William Kerr, "Ethnic Innovation and U.S. Multinational Firm Activity", Management Science 59:7 (2013), 1529-1544.

[25] Freeman, Richard, "People Flows in Globalization", Journal of Economic Perspectives 20:2 (2006), 145-170.

[26] Friedberg, Rachel, "The Impact of Mass Migration on the Israeli Labor Market", Quarterly Journal of Economics 116:4 (2001), 1373-1408.

[27] Friedberg, Rachel, and Jennifer Hunt, "The Impact of Immigrants on Host Country Wages, Employment and Growth", Journal of Economic Perspectives 9:2 (1995), 23-44.

[28] Furman, Jeffrey, Michael Porter, and Scott Stern, "The Determinants of National Innovative Capacity", Research Policy 31:6 (2002), 899-933.

[29] Gabaix, Xavier, "The Granular Origins of Aggregate Fluctuations", Econometrica 79:3 (2011), 733-772.

[30] Gaule, Patrick, and Mario Piacentini, "Chinese Graduate Students and U.S. Scientific Productivity", Review of Economics and Statistics 95:2 (2013), 698-701.

[31] Hira, Ron, "The H-1B and L-1 Visa programs: Out of Control", EPI Policy Paper (2010).

[32] Hunt, Jennifer, "The Impact of the 1962 Repatriates from Algeria on the French Labor Market", Industrial and Labor Relations Review 45:3 (1992), 556-572.

[33] Hunt, Jennifer, "Which Immigrants are Most Innovative and Entrepreneurial? Distinctions by Entry Visa", Journal of Labor Economics 29:3 (2011), 417-457.

[34] Hunt, Jennifer, "Does the United States Admit the Best and Brightest Computer and Engineering Workers", Working Paper (2012).

[35] Hunt, Jennifer, and Marjolaine Gauthier-Loiselle, "How Much Does Immigration Boost Innovation?", American Economic Journal: Macroeconomics 2:2 (2010), 31-56.

[36] Kerr, Sari Pekkala, and William Kerr, "Economic Impacts of Immigration: A Survey", Finnish Economics Papers 24:1 (2011), 1-32. 
[37] Kerr, William, "Ethnic Scientific Communities and International Technology Diffusion", Review of Economics and Statistics 90:3 (2008), 518-537.

[38] Kerr, William, "Breakthrough Inventions and Migrating Clusters of Innovation", Journal of Urban Economics 67:1 (2010), 46-60.

[39] Kerr, William, "U.S. High-Skilled Immigration, Innovation, and Entrepreneurship: Empirical Approaches and Evidence", NBER Working Paper (2013).

[40] Kerr, William, and Shihe Fu, "The Survey of Industrial R\&D-Patent Database Link Project", Journal of Technology Transfer 33:2 (2008), 173-186.

[41] Kerr, William, and William Lincoln, "The Supply Side of Innovation: H-1B Visa Reforms and U.S. Ethnic Invention", Journal of Labor Economics 28:3 (2010), 473-508.

[42] Kerr, William, William Lincoln, and Prachi Mishra, "The Dynamics of Firm Lobbying", American Economic Journal: Economic Policy (2013), forthcoming.

[43] Lach, Saul, "Immigration and Prices", Journal of Political Economy 115:4 (2007), 548-587.

[44] Lewis, Ethan, "Immigration, Skill Mix, and Capital-Skill Complementarity", Quarterly Journal of Economics 126:2 (2011), 1029-1069.

[45] Lofstrom, Mangus, and Joseph Hayes, "H-1Bs: How Do They Stack Up to US Born Workers?", IZA Discussion Paper No 6259 (2011).

[46] Longhi, Simonetta, Peter Nijkamp, and Jacques Poot, "A Meta-Analytic Assessment of the Effects of Immigration on Wages", Journal of Economic Surveys 19:3 (2005), 451-477.

[47] Longhi, Simonetta, Peter Nijkamp, and Jacques Poot, "The Impact of Immigration on the Employment of Natives in Regional Labour Markets: A Meta-Analysis", IZA Working Paper 2044 (2006).

[48] Lowell, B. Lindsay, and Bryan Christian, "The Characteristics of Employers of H-1Bs", Institute for the Study of International Migration Working Paper (2000).

[49] Lubostky, Darren, "Chutes or Ladders? A Longitudinal Study of Immigrant Earnings", Journal of Political Economy 115:5 (2007), 820-867.

[50] Mandorff, Martin, "Social Networks, Ethnicity, and Occupation", Working Paper (2007).

[51] Matloff, Norman, "On the Need for Reform of the H-1B Non-Immigrant Work Visa in Computer-Related Occupations", University of Michigan Journal of Law Reform 36:4 (2003), 815-914.

[52] Mithas, Sunil, and Henry Lucas, "Are Foreign IT Workers Cheaper? U.S. Visa Policies and Compensation of Information Technology Professionals", Management Science 56:5 (2010), 745-765.

[53] Moser, Petra, Alessandra Voena, and Fabian Waldinger, "German Jewish Emigres and U.S. Invention", Working Paper (2012).

[54] Nathan, Max, "Ethnic Inventors, Diversity and Innovation in the UK: Evidence from Patents Microdata", Working Paper (2011). 
[55] National Foundation for American Policy, "H-1B Visas and Job Creation", Policy Brief (2008).

[56] National Foundation for American Policy, "H-1B Visas by the Numbers: 2010 and Beyond", Policy Brief (2010).

[57] Olney, William, "Immigration and Firm Expansion", Journal of Regional Science 53:1 (2012), 142-157.

[58] Ottaviano, Gianmarco, and Giovanni Peri, "Rethinking the Effect of Immigration on Wages", Journal of the European Economic Association 10:1 (2012), 152-197.

[59] Ozden, Caglar, and Mathis Wagner, "Immigrants versus Natives? Displacement and Job Creation in Malaysia", Working Paper (2013).

[60] Pallais, Amanda, "Inefficient Hiring in Entry-Level Labor Markets", Working Paper (2011).

[61] Parrotta, Pierpaolo, Dario Pozzoli, and Mariola Pytlikova, "The Nexus between Labor Diversity and Firm's Innovation", Working Paper (2013).

[62] Peri, Giovanni, "Rethinking the Area Approach: Immigrants and the Labor Market in California, 1960-2005", Journal of International Economics 84:1 (2011), 1-14.

[63] Peri, Giovanni, "The Effect Of Immigration On Productivity: Evidence From U.S. States", Review of Economics and Statistics 94:1 (2012), 348-358.

[64] Peri, Giovanni, Kevin Shih, and Chad Sparber, "STEM Workers, H-1B Visas and Productivity in US Cities", Working Paper (2013).

[65] Peri, Giovanni, and Chad Sparber, "Task Specialization, Immigration and Wages", American Economic Journal: Applied Economics 1:3 (2009), 135-169.

[66] Peri, Giovanni, and Chad Sparber, "Highly-Educated Immigrants and Native Occupational Choice", Industrial Relations 50:3 (2011), 385-411.

[67] Ruiz, Neil, Jill Wilson, and Shyamali Choudhury, "Geography of H-1B Workers: Demand for High-Skilled Foreign Labor in U.S. Metropolitan Areas", Brookings Report (2012).

[68] Schleifer, Andrei, and Lawrence Summers, "Breaches of Trust in Hostile Takeovers", in Auerbach, Alan (ed.) Corporate Takeovers: Causes and Consequences (Chicago, IL: University of Chicago Press, 1988).

[69] Stephan, Paula, and Sharon Levin, "Exceptional Contributions to US Science by the Foreign-Born and Foreign-Educated", Population Research and Policy Review 20:1 (2001), 59-79.

[70] Tervio, Marko, "Superstars and Mediocrities: Market Failure in the Discovery of Talent", Review of Economic Studies 76:2 (2009), 829-850.

[71] Wadhwa, Vivek, "Silicon Valley's Dark Secret: It's All About Age", TechCrunch Post (2010). 


\section{Figure 1: LEHD state coverage}

\section{Stars indicate primary sample of 18 states whose coverage begins by 1995}

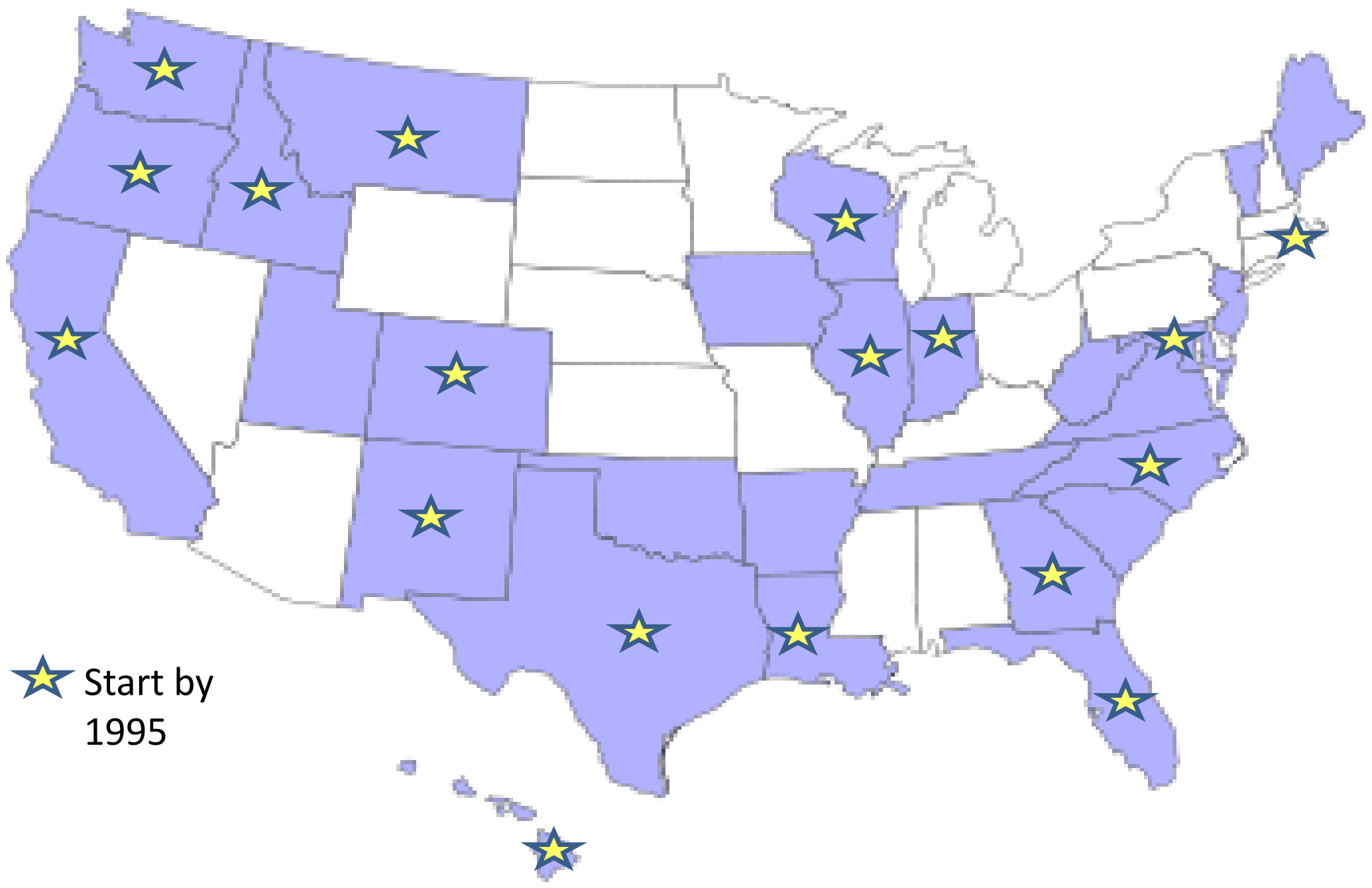




\section{Figure 2: H-1B population estimates and numerical caps}

Population estimates on left-hand axis; numerical caps on right-hand axis

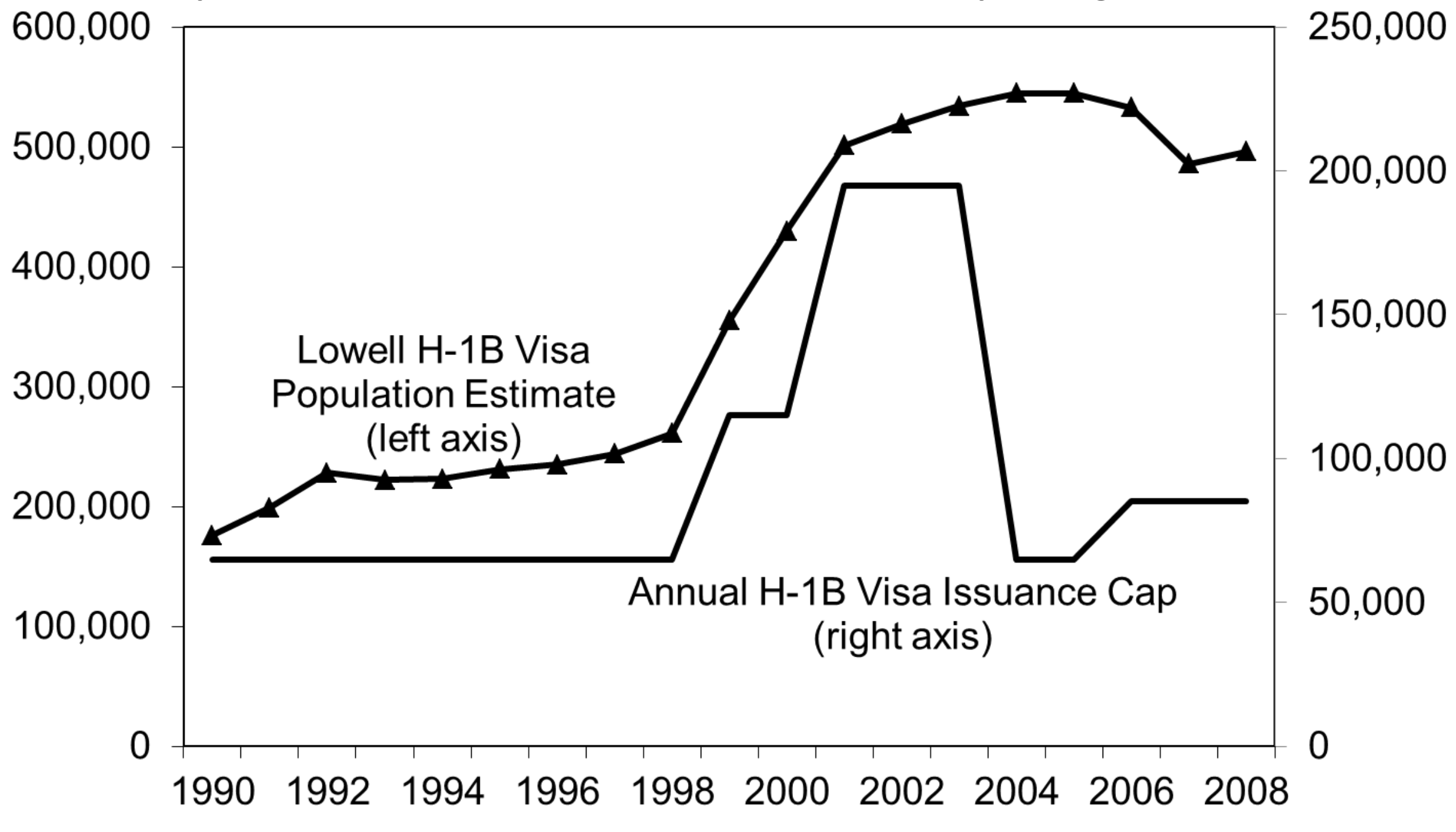




\section{Figure 3: Immigration and age profiles in computer occupations}

National trends from CPS comparing top five H-1B states to the rest of country

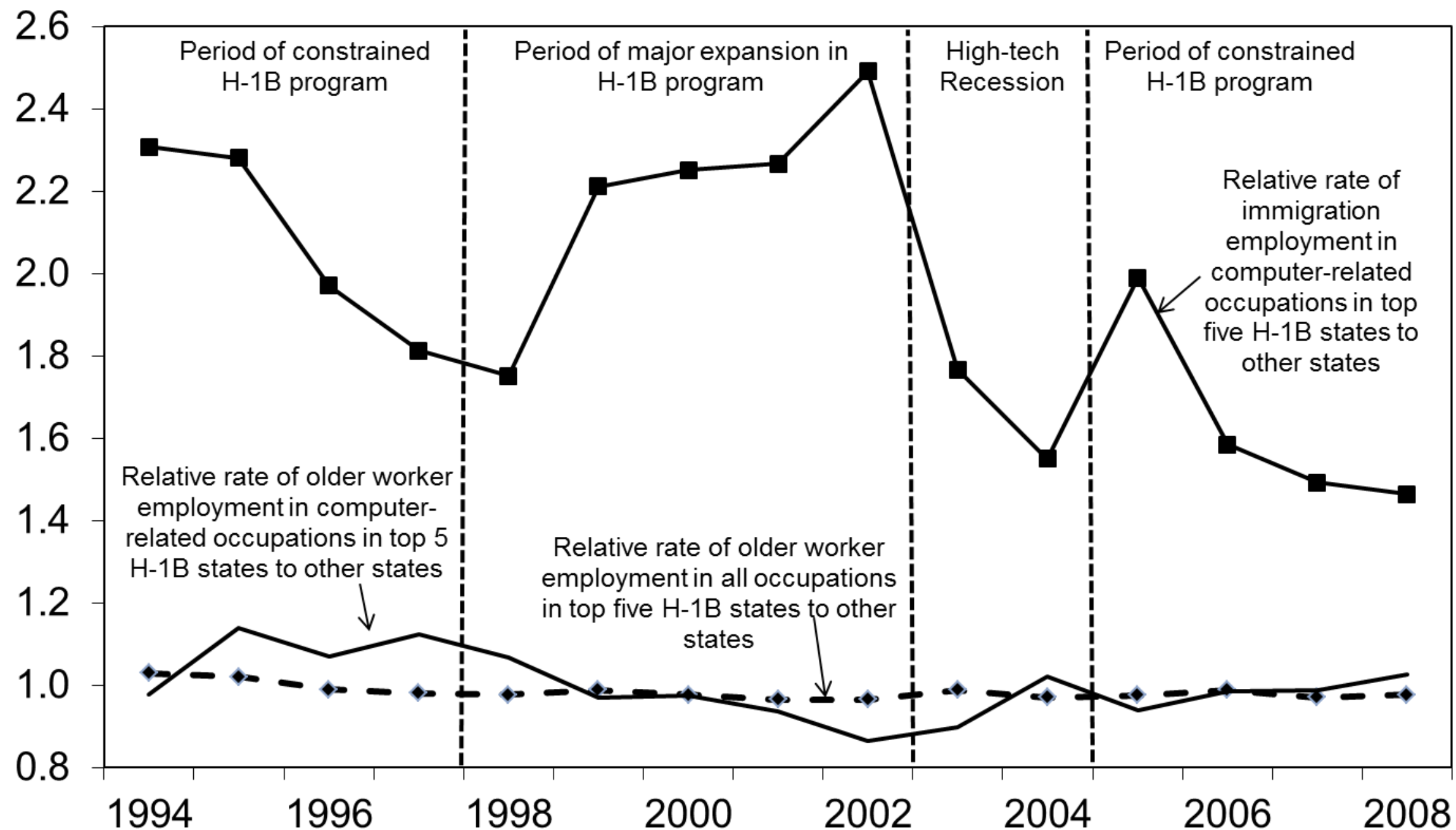

Notes: Relative rates for older workers are calculated by comparing the share of workers aged 40-65 in the top five H-1B states (CA, DC, MA, NJ, NY) to the share in the other 45 states. Relative immigration rates are similarly defined. Data are from the Current Population Survey. Caution should be exercised on the levels between 2002 and 2003 as the CPS was redesigned during this period. 
Table 1: Descriptive statistics

\begin{tabular}{|c|c|c|c|c|}
\hline & \multicolumn{2}{|c|}{ Full sample } & \multicolumn{2}{|c|}{ Top patenting sample } \\
\hline & Mean & Standard deviation & Mean & Standard deviation \\
\hline Total employment & 21,238 & 29,029 & 19,631 & 30,041 \\
\hline Immigrant share & $19.8 \%$ & $11.7 \%$ & $21.9 \%$ & $12.9 \%$ \\
\hline Skilled employment share & $50.0 \%$ & $23.8 \%$ & $64.7 \%$ & $18.3 \%$ \\
\hline Skilled employment & 9,887 & 15,487 & 12,921 & 21,383 \\
\hline Native over-40 share & $50.3 \%$ & $15.6 \%$ & $47.5 \%$ & $15.2 \%$ \\
\hline Native under-40 share & $31.2 \%$ & $12.5 \%$ & $31.5 \%$ & $9.6 \%$ \\
\hline Immigrant over-40 share & $9.0 \%$ & $6.0 \%$ & $9.5 \%$ & $5.4 \%$ \\
\hline Immigrant under-40 share & $9.5 \%$ & $7.8 \%$ & $11.5 \%$ & $9.0 \%$ \\
\hline Hiring rate & $13.1 \%$ & $8.3 \%$ & $12.7 \%$ & $7.9 \%$ \\
\hline Departure rate & $14.4 \%$ & $7.5 \%$ & $12.5 \%$ & $5.9 \%$ \\
\hline Medium-skilled employment & 7,928 & 11,528 & 5,342 & 8,037 \\
\hline Initial LCA dependency & $0.8 \%$ & $1.7 \%$ & $1.0 \%$ & $1.5 \%$ \\
\hline Initial Chinese/Indian share & $17.6 \%$ & $12.2 \%$ & $19.7 \%$ & $11.8 \%$ \\
\hline STEM Occupation share & $12.1 \%$ & $16.0 \%$ & $18.2 \%$ & $16.8 \%$ \\
\hline
\end{tabular}

Notes: Descriptive statistics are taken from the LEHD. The sample is an unbalanced panel of 319 firms and their employments in 18 states during the 1995-2008 period. State inclusion is dictated by the LEHD data coverage, and firms must satisfy minimum employment coverage ratios in these states to be included. The sample includes major patenting firms and major U.S. employers as described in the text. Skilled workers are defined as those with median annual earnings over the 1995-2008 period exceeding \$50,000 in constant 2008 dollars. Medium-skilled workers are defined as those with median annual earnings over the 1995-2008 period of \$25,000-\$50,000 in constant 2008 dollars. Younger workers are those less than 40 years old. 


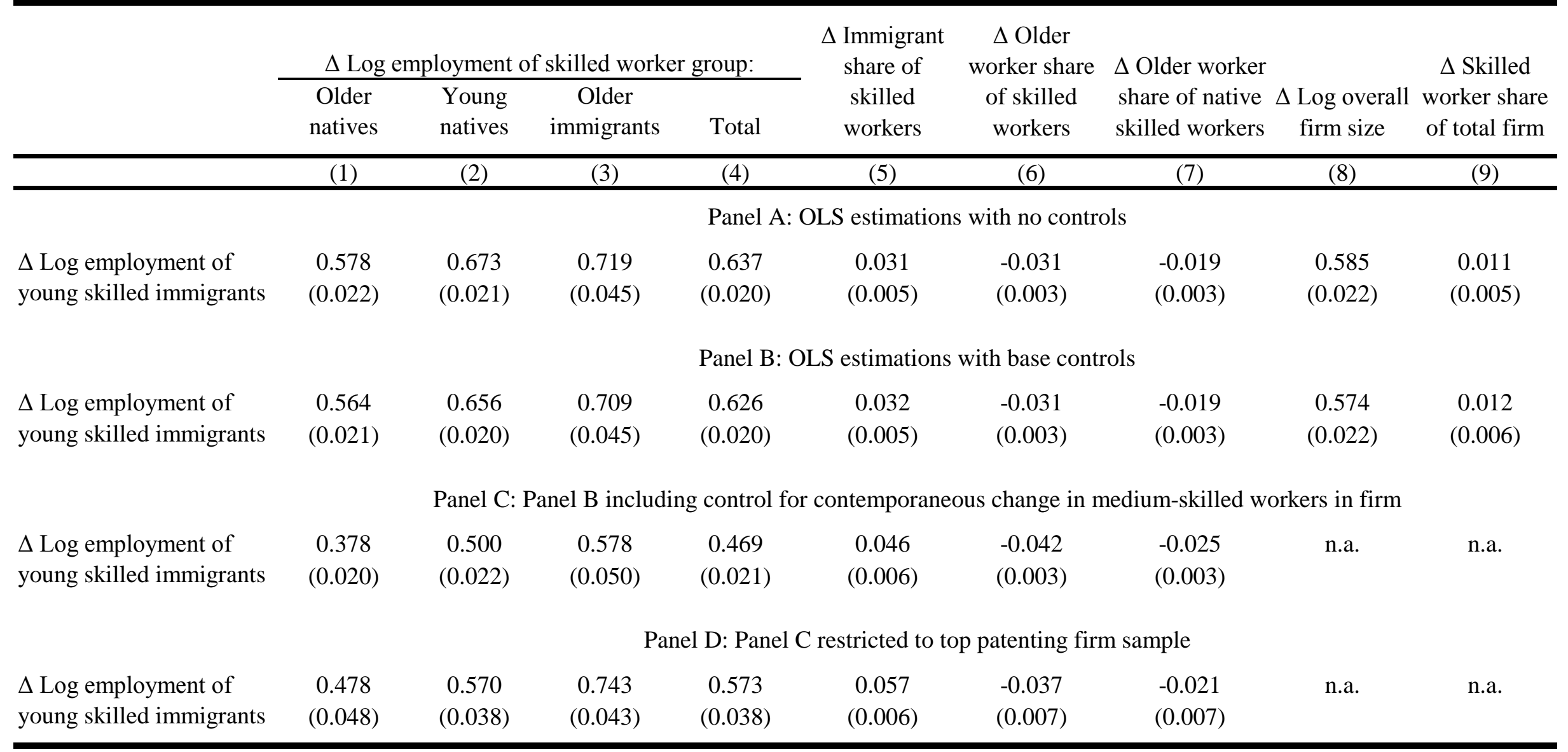

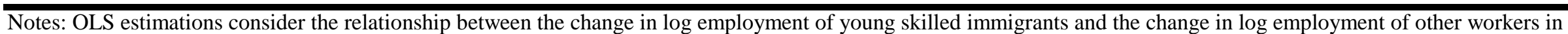

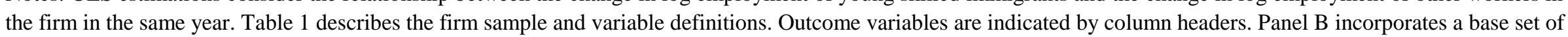

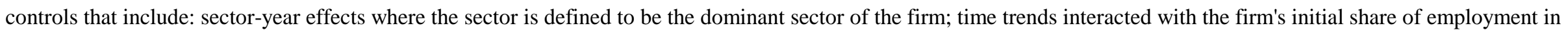
each sector; a time trend interacted with the firm's initial patent per worker intensity; an age-education immigration factor developed through the firm's initial skilled

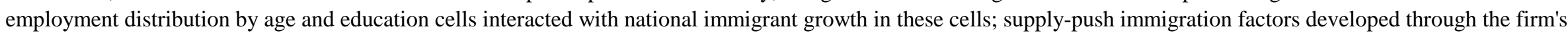

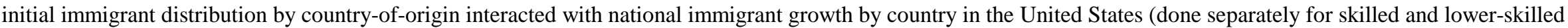

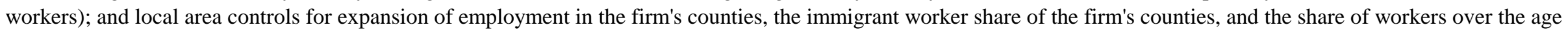

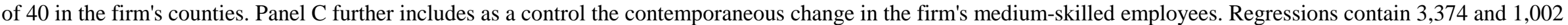

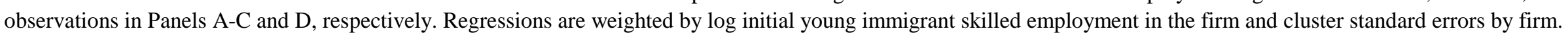


Table 3a: OLS estimations of worker hiring and departing margins

\begin{tabular}{|c|c|c|c|c|c|c|c|c|}
\hline & \multicolumn{4}{|c|}{$\Delta$ Log hires of skilled worker group: } & \multicolumn{4}{|c|}{$\Delta$ Log departures of skilled worker group: } \\
\hline & $\begin{array}{l}\text { Older } \\
\text { natives }\end{array}$ & $\begin{array}{l}\text { Young } \\
\text { natives }\end{array}$ & $\begin{array}{c}\text { Older } \\
\text { immigrants }\end{array}$ & $\begin{array}{c}\text { Young } \\
\text { immigrants }\end{array}$ & $\begin{array}{c}\text { Older } \\
\text { natives }\end{array}$ & $\begin{array}{r}\text { Young } \\
\text { natives }\end{array}$ & $\begin{array}{c}\text { Older } \\
\text { immigrants }\end{array}$ & $\begin{array}{c}\text { Young } \\
\text { immigrants }\end{array}$ \\
\hline & (1) & (2) & (3) & (4) & (5) & (6) & (7) & (8) \\
\hline \multirow{3}{*}{$\begin{array}{l}\Delta \text { Log hiring of young } \\
\text { skilled immigrants }\end{array}$} & \multicolumn{8}{|c|}{ Panel A: OLS estimations with no controls } \\
\hline & $\begin{array}{c}0.579 \\
(0.026)\end{array}$ & $\begin{array}{c}0.591 \\
(0.024)\end{array}$ & $\begin{array}{c}0.672 \\
(0.030)\end{array}$ & n.a. & $\begin{array}{l}-0.008 \\
(0.020)\end{array}$ & $\begin{array}{c}0.027 \\
(0.020)\end{array}$ & $\begin{array}{l}-0.001 \\
(0.027)\end{array}$ & $\begin{array}{c}0.085 \\
(0.026)\end{array}$ \\
\hline & \multicolumn{8}{|c|}{ Panel B: OLS estimations with base controls } \\
\hline $\begin{array}{l}\Delta \text { Log hiring of young } \\
\text { skilled immigrants }\end{array}$ & $\begin{array}{c}0.577 \\
(0.027)\end{array}$ & $\begin{array}{c}0.584 \\
(0.024)\end{array}$ & $\begin{array}{c}0.670 \\
(0.030)\end{array}$ & n.a. & $\begin{array}{l}-0.021 \\
(0.020)\end{array}$ & $\begin{array}{c}0.012 \\
(0.020)\end{array}$ & $\begin{array}{l}-0.013 \\
(0.027)\end{array}$ & $\begin{array}{c}0.069 \\
(0.027)\end{array}$ \\
\hline \multirow{3}{*}{$\begin{array}{l}\Delta \text { Log hiring of young } \\
\text { skilled immigrants }\end{array}$} & \multicolumn{8}{|c|}{ Panel C: Panel B including control for contemporaneous change in medium-skilled workers in firm } \\
\hline & $\begin{array}{c}0.527 \\
(0.028)\end{array}$ & $\begin{array}{c}0.535 \\
(0.025)\end{array}$ & $\begin{array}{c}0.642 \\
(0.032)\end{array}$ & n.a. & $\begin{array}{l}-0.122 \\
(0.021)\end{array}$ & $\begin{array}{l}-0.083 \\
(0.021)\end{array}$ & $\begin{array}{l}-0.114 \\
(0.028)\end{array}$ & $\begin{array}{l}-0.023 \\
(0.027)\end{array}$ \\
\hline & \multicolumn{8}{|c|}{ Panel D: Panel C restricted to top patenting firm sample } \\
\hline $\begin{array}{l}\Delta \text { Log hiring of young } \\
\text { skilled immigrants }\end{array}$ & $\begin{array}{c}0.590 \\
(0.056)\end{array}$ & $\begin{array}{c}0.603 \\
(0.042)\end{array}$ & $\begin{array}{c}0.746 \\
(0.051)\end{array}$ & n.a. & $\begin{array}{l}-0.199 \\
(0.043)\end{array}$ & $\begin{array}{l}-0.161 \\
(0.038)\end{array}$ & $\begin{array}{l}-0.236 \\
(0.054)\end{array}$ & $\begin{array}{l}-0.110 \\
(0.041)\end{array}$ \\
\hline
\end{tabular}

Notes: See Table 2. OLS estimations consider the relationship between log changes in young skilled immigrant hiring and log changes in the hiring/departures of other skilled workers in the firm in the same year. 
Table 3b: Continuation of Table 3a

\begin{tabular}{|c|c|c|c|c|c|}
\hline & $\begin{array}{c}\Delta \text { Log employment of } \\
\text { older native skilled } \\
\text { workers }\end{array}$ & $\begin{array}{c}\Delta \text { Log employment of } \\
\text { young native skilled } \\
\text { workers }\end{array}$ & $\begin{array}{l}\Delta \text { Log employment of } \\
\text { older skilled immigrant } \\
\text { workers }\end{array}$ & $\begin{array}{c}\Delta \text { Log employment of } \\
\text { young skilled immigrant } \\
\text { workers }\end{array}$ & $\begin{array}{c}\Delta \text { Log total employment } \\
\text { of skilled workers }\end{array}$ \\
\hline & $(1)$ & $(2)$ & $(3)$ & (4) & $(5)$ \\
\hline \multirow{3}{*}{$\begin{array}{l}\Delta \text { Log hiring of young } \\
\text { skilled immigrants }\end{array}$} & \multicolumn{5}{|c|}{ Panel A: OLS estimations with no controls } \\
\hline & $\begin{array}{c}0.100 \\
(0.009)\end{array}$ & $\begin{array}{c}0.122 \\
(0.009)\end{array}$ & $\begin{array}{c}0.125 \\
(0.011)\end{array}$ & $\begin{array}{c}0.194 \\
(0.011)\end{array}$ & $\begin{array}{c}0.115 \\
(0.009)\end{array}$ \\
\hline & \multicolumn{5}{|c|}{ Panel B: OLS estimations with base controls } \\
\hline $\begin{array}{l}\Delta \text { Log hiring of young } \\
\text { skilled immigrants }\end{array}$ & $\begin{array}{c}0.095 \\
(0.009)\end{array}$ & $\begin{array}{c}0.115 \\
(0.008)\end{array}$ & $\begin{array}{c}0.120 \\
(0.010)\end{array}$ & $\begin{array}{c}0.190 \\
(0.011)\end{array}$ & $\begin{array}{c}0.110 \\
(0.009)\end{array}$ \\
\hline \multirow{3}{*}{$\begin{array}{l}\Delta \text { Log hiring of young } \\
\text { skilled immigrants }\end{array}$} & \multicolumn{5}{|c|}{ Panel C: Panel B including control for contemporaneous change in medium-skilled workers in firm } \\
\hline & $\begin{array}{c}0.038 \\
(0.006)\end{array}$ & $\begin{array}{c}0.058 \\
(0.005)\end{array}$ & $\begin{array}{c}0.062 \\
(0.007)\end{array}$ & $\begin{array}{c}0.137 \\
(0.009)\end{array}$ & $\begin{array}{c}0.054 \\
(0.005)\end{array}$ \\
\hline & \multicolumn{5}{|c|}{ Panel D: Panel C restricted to top patenting firm sample } \\
\hline $\begin{array}{l}\Delta \text { Log hiring of young } \\
\text { skilled immigrants }\end{array}$ & $\begin{array}{c}0.043 \\
(0.014)\end{array}$ & $\begin{array}{c}0.062 \\
(0.011)\end{array}$ & $\begin{array}{c}0.058 \\
(0.010)\end{array}$ & $\begin{array}{c}0.122 \\
(0.010)\end{array}$ & $\begin{array}{c}0.061 \\
(0.011)\end{array}$ \\
\hline
\end{tabular}

Notes: See Table 3a. 
Table 4: IV estimations without medium-skilled workforce control

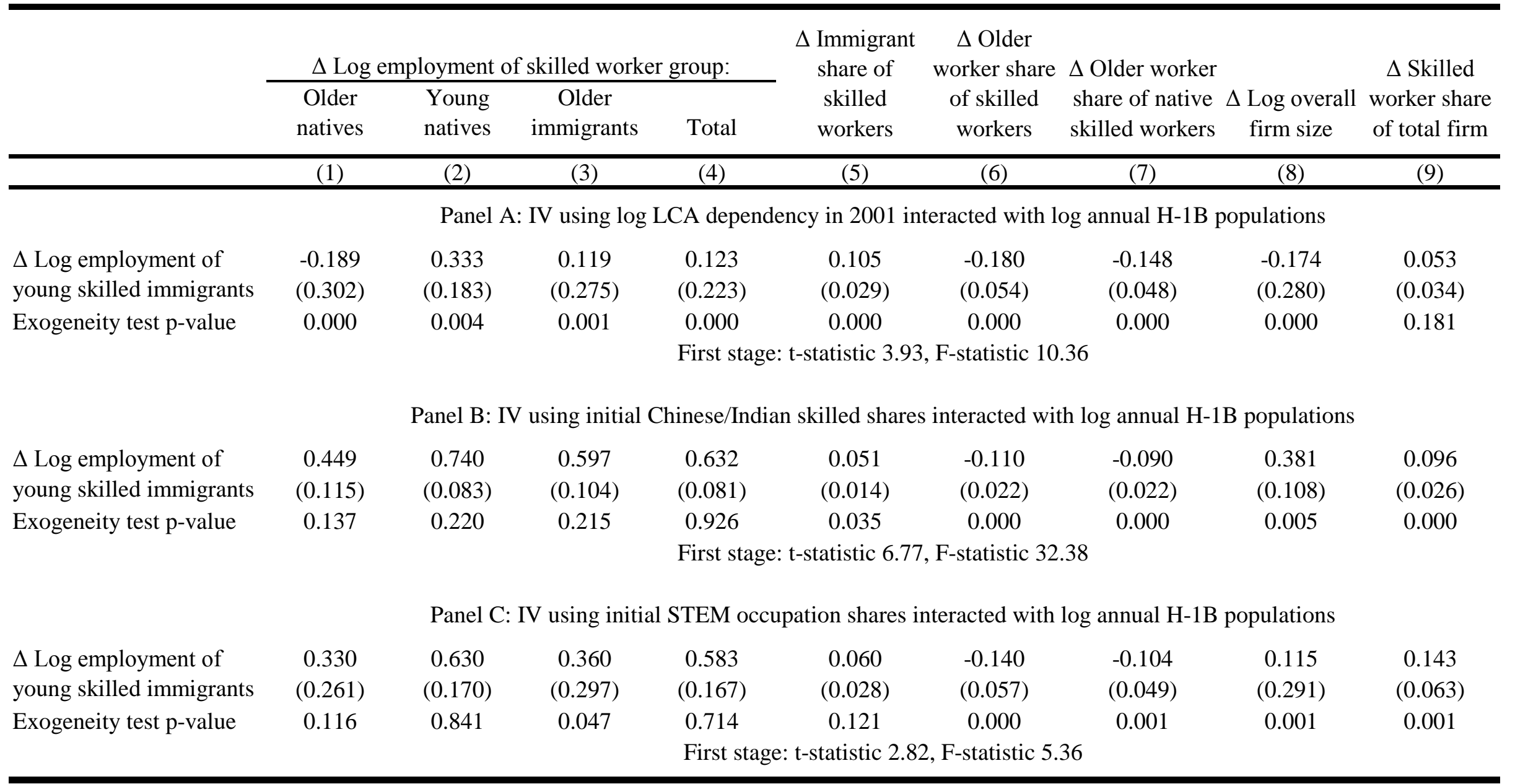

Notes: See Table 2. Instruments utilizing H-1B fluctuations interact a fixed dependency on the program for each firm with a measure of the national size of the H-1B

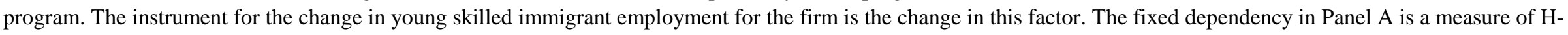

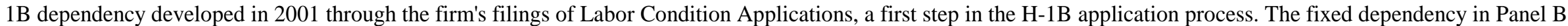

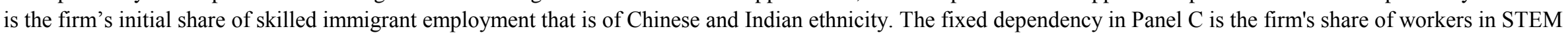

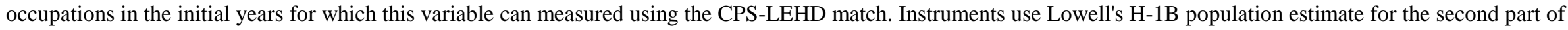
the interaction. Regressions include the full set of controls similar to Panel C of Table 2 . The null hypothesis in Wu-Hausman exogeneity tests is that the instrumented regressors are exogenous. 
Table 5: IV estimations with medium-skilled workforce control

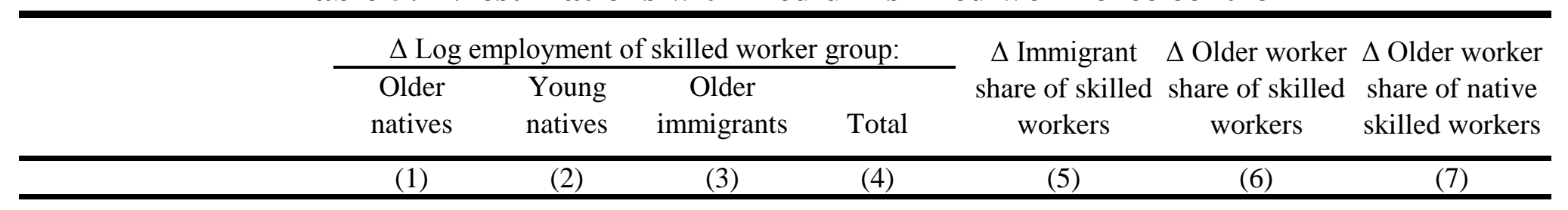

Panel A: IV using log LCA dependency in 2001 interacted with log annual H-1B populations

$\begin{array}{lccccccc}\Delta \text { Log employment of } & -0.051 & 0.410 & 0.223 & 0.224 & 0.093 & -0.159 & -0.131 \\ \text { young skilled immigrants } & (0.161) & (0.111) & (0.180) & (0.123) & (0.017) & (0.034) & (0.033) \\ \text { Exogeneity test p-value } & 0.000 & 0.328 & 0.004 & 0.001 & 0.000 & 0.000 & 0.000\end{array}$

young s

First stage: t-statistic 4.84, F-statistic 23.36

Panel B: IV using initial Chinese/Indian skilled shares interacted with log annual H-1B populations

$\begin{array}{lccccccc}\Delta \text { Log employment of } & 0.442 & 0.736 & 0.591 & 0.627 & 0.052 & -0.112 & -0.092 \\ \text { young skilled immigrants } & (0.098) & (0.077) & (0.098) & (0.071) & (0.013) & (0.018) & (0.020) \\ \text { Exogeneity test p-value } & 0.514 & 0.003 & 0.909 & 0.035 & 0.025 & 0.000 & 0.001\end{array}$

$\begin{array}{llllcc}\text { Exogeneity test p-value } & 0.514 & 0.003 & 0.909 & 0.035 & 0.025 \\ & & & \text { First stage: t-statistic } & \text { 7.02, F-statistic 49.10 }\end{array}$

Panel C: IV using initial STEM occupation shares interacted with log annual H-1B populations

$\begin{array}{lccccccc}\Delta \text { Log employment of } & 0.414 & 0.676 & 0.446 & 0.632 & 0.052 & -0.122 & -0.090 \\ \text { young skilled immigrants } & (0.173) & (0.125) & (0.197) & (0.118) & (0.021) & (0.036) & (0.034) \\ \text { Exogeneity test p-value } & 0.838 & 0.211 & 0.481 & 0.225 & 0.773 & 0.008 & 0.039\end{array}$

First stage: t-statistic 3.49, F-statistic 12.14

Notes: See Table 4. Estimations include a control for contemporaneous change in medium-skilled workers in firm. 
Table 6: Table 5's IV analysis using H-1B cap summations

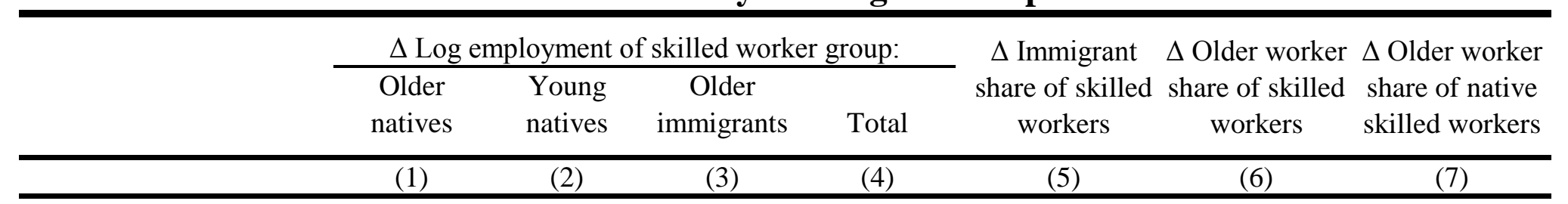

Panel A: IV using log LCA/employee dependency in 2001 interacted with log annual H-1B cap

$\begin{array}{lccccccc}\Delta \text { Log employment of } & 0.121 & 0.537 & 0.349 & 0.400 & 0.075 & -0.149 & -0.129 \\ \text { young skilled immigrants } & (0.114) & (0.092) & (0.148) & (0.085) & (0.015) & (0.030) & (0.032) \\ \text { Exogeneity test p-value } & 0.018 & 0.635 & 0.109 & 0.457 & 0.031 & 0.000 & 0.000\end{array}$

Exogeneity test p-value

0.018

First stage: t-statistic 4.77, F-statistic 22.71

Panel B: IV using initial Chinese/Indian skilled shares interacted with log annual H-1B cap summations

$\begin{array}{lccccccc}\Delta \text { Log employment of } & 0.423 & 0.785 & 0.619 & 0.654 & 0.051 & -0.130 & -0.116 \\ \text { young skilled immigrants } & (0.109) & (0.091) & (0.135) & (0.078) & (0.016) & (0.024) & (0.026) \\ \text { Exogeneity test p-value } & 0.678 & 0.001 & 0.761 & 0.023 & 0.716 & 0.000 & 0.000\end{array}$

First stage: t-statistic 5.37, F-statistic 28.78

Panel C: IV using initial STEM occupation shares interacted with log annual H-1B cap summations

$\begin{array}{lccccccc}\Delta \text { Log employment of } & 0.391 & 0.741 & 0.583 & 0.649 & 0.052 & -0.131 & -0.124 \\ \text { young skilled immigrants } & (0.168) & (0.134) & (0.172) & (0.116) & (0.024) & (0.035) & (0.040) \\ \text { Exogeneity test p-value } & 0.941 & 0.083 & 0.976 & 0.149 & 0.781 & 0.002 & 0.002\end{array}$

First stage: t-statistic 3.26, F-statistic 10.59

Notes: See Table 5. Instruments use the summation of the previous six years' H-1B caps as a second version of the program's national size. 
Table 7a: Further robustness checks on Table 5's IV analysis with population trends

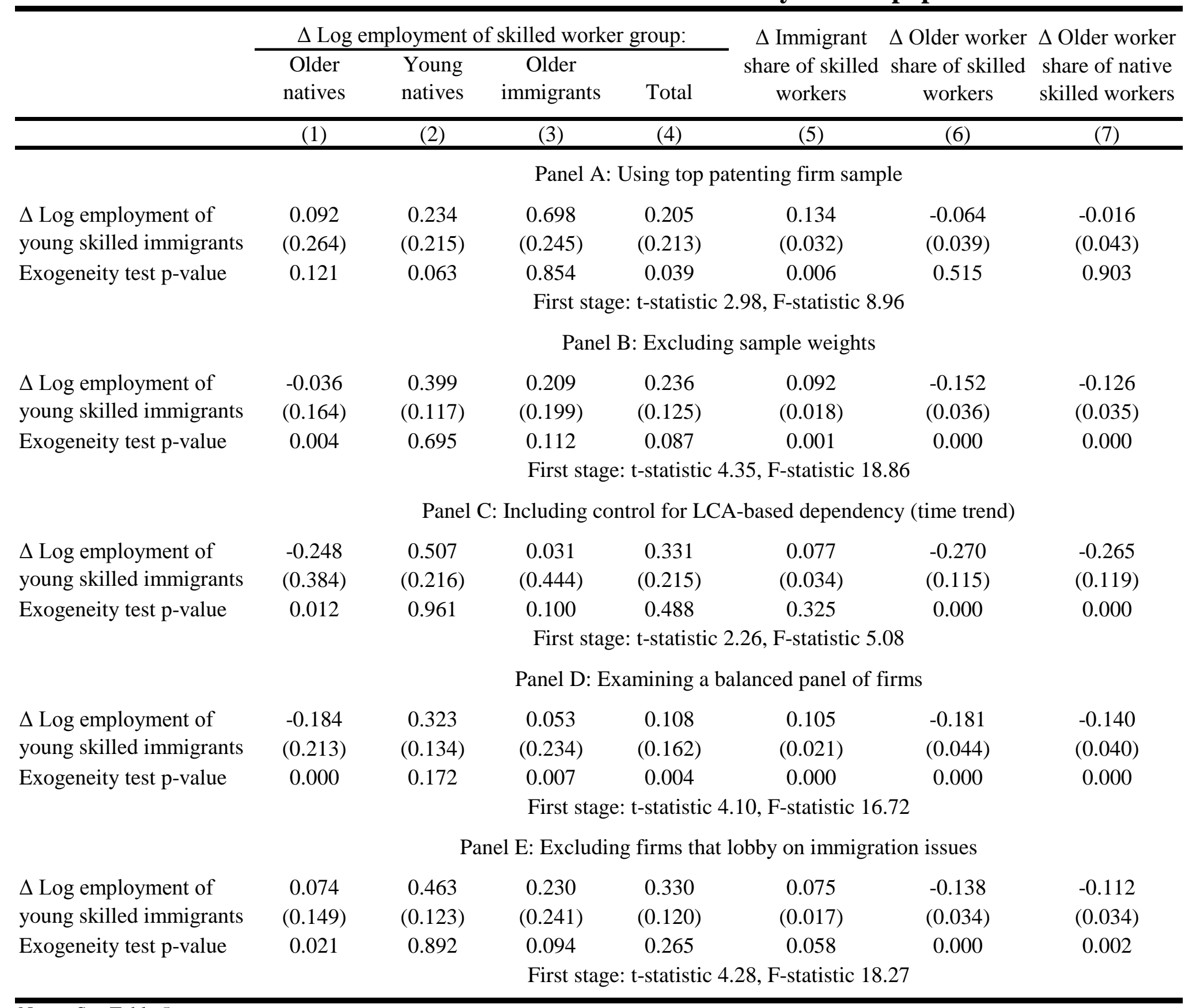

Notes: See Table 5. 
Table 7b: Further robustness checks on Table 6's IV analysis with cap summations

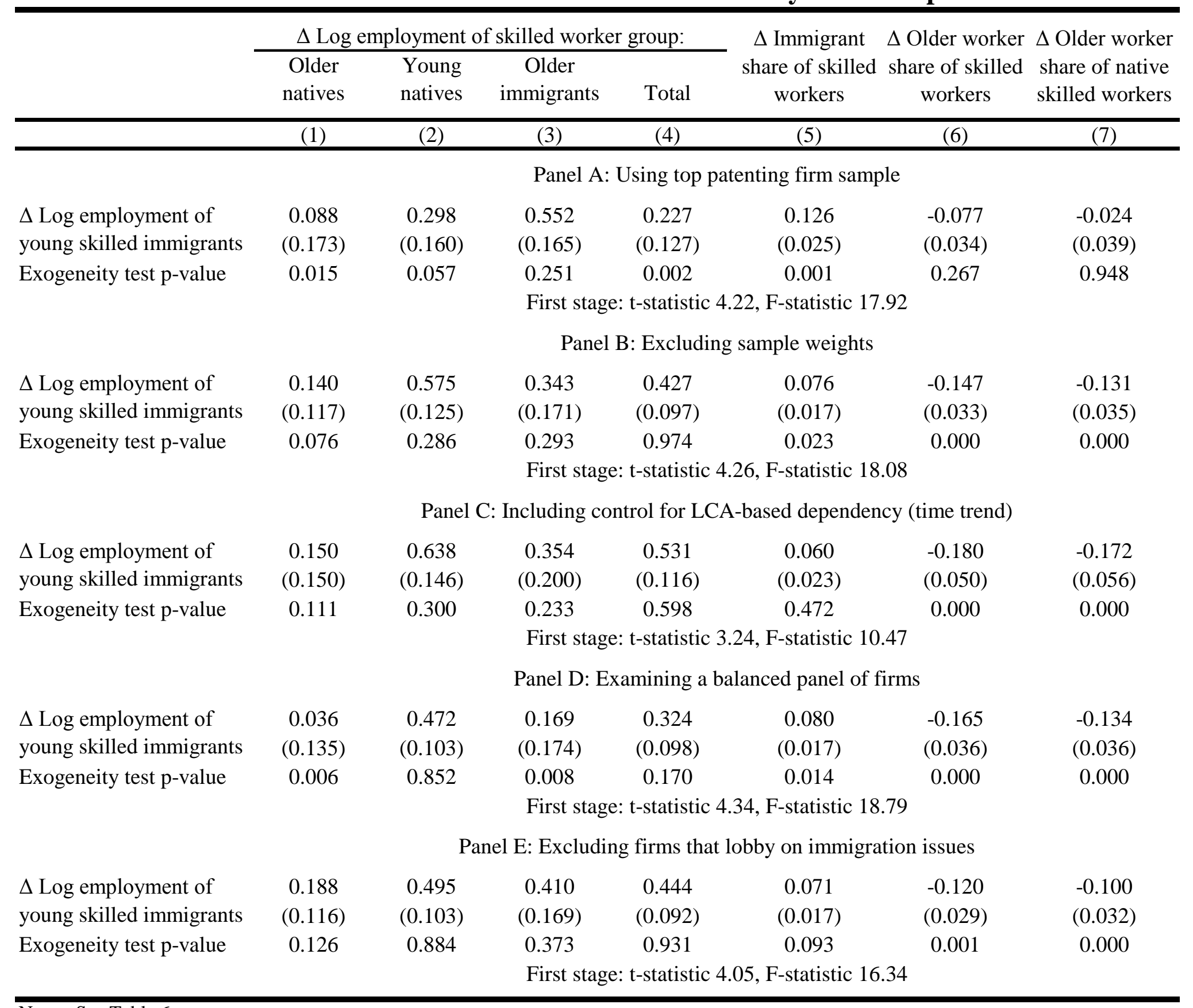

Notes: See Table 6. 
Table 8: Departure rates by occupation, age, and salary level

\begin{tabular}{|c|c|c|c|c|c|}
\hline & \multicolumn{4}{|c|}{$(0,1)$ Worker departs from the firm } & \multirow{2}{*}{$\begin{array}{c}\text { Column } 4 \text { with } \\
\text { DV of }(0,1) \\
\text { worker hired in } \\
\text { year }\end{array}$} \\
\hline & $\begin{array}{c}\text { Estimation } \\
\text { including age } \\
\text { and year fixed } \\
\text { effects }\end{array}$ & $\begin{array}{c}\text { Estimation } \\
\text { including age } \\
\text { and firm-year } \\
\text { fixed effects }\end{array}$ & $\begin{array}{c}\text { Estimation } \\
\text { including age } \\
\text { and firm-year } \\
\text { fixed effects }\end{array}$ & $\begin{array}{c}\text { Estimation } \\
\text { including age- } \\
\text { occupation and } \\
\text { firm-year fixed } \\
\text { effects }\end{array}$ & \\
\hline & $(1)$ & $(2)$ & (3) & $(4)$ & $(5)$ \\
\hline $\begin{array}{l}\Delta \text { Log hiring of young skilled } \\
\text { immigrants in the firm }\end{array}$ & $\begin{array}{l}-0.072 \\
(0.025)\end{array}$ & \multicolumn{4}{|c|}{ (Reference category: young, non-STEM occupations) } \\
\hline $\begin{array}{l}\mathrm{x} \text { older worker in STEM } \\
\text { occupations }\end{array}$ & $\begin{array}{c}0.073 \\
(0.038)\end{array}$ & $\begin{array}{c}0.056 \\
(0.032)\end{array}$ & & & \\
\hline $\mathrm{x}$ higher wage & & & $\begin{array}{c}0.119 \\
(0.041)\end{array}$ & $\begin{array}{c}0.102 \\
(0.039)\end{array}$ & $\begin{array}{l}-0.005 \\
(0.036)\end{array}$ \\
\hline $\mathrm{x}$ lower wage & & & $\begin{array}{l}-0.076 \\
(0.074)\end{array}$ & $\begin{array}{l}-0.089 \\
(0.079)\end{array}$ & $\begin{array}{l}-0.020 \\
(0.059)\end{array}$ \\
\hline $\begin{array}{l}\text { x younger worker in STEM } \\
\text { occupations }\end{array}$ & $\begin{array}{c}0.056 \\
(0.045)\end{array}$ & $\begin{array}{c}0.025 \\
(0.041)\end{array}$ & & & \\
\hline $\mathrm{x}$ higher wage & & & $\begin{array}{c}0.015 \\
(0.044)\end{array}$ & $\begin{array}{c}0.013 \\
(0.039)\end{array}$ & $\begin{array}{l}-0.043 \\
(0.057)\end{array}$ \\
\hline $\mathrm{x}$ lower wage & & & $\begin{array}{c}0.060 \\
(0.092)\end{array}$ & $\begin{array}{c}0.033 \\
(0.096)\end{array}$ & $\begin{array}{c}0.075 \\
(0.088)\end{array}$ \\
\hline $\begin{array}{l}\mathrm{x} \text { older worker in non-STEM } \\
\text { occupations }\end{array}$ & $\begin{array}{c}0.021 \\
(0.020)\end{array}$ & $\begin{array}{c}0.011 \\
(0.018)\end{array}$ & & & \\
\hline $\mathrm{x}$ higher wage & & & $\begin{array}{c}0.086 \\
(0.026)\end{array}$ & $\begin{array}{c}0.086 \\
(0.027)\end{array}$ & $\begin{array}{l}-0.004 \\
(0.033)\end{array}$ \\
\hline x lower wage & & & $\begin{array}{l}-0.024 \\
(0.023)\end{array}$ & $\begin{array}{l}-0.023 \\
(0.023)\end{array}$ & $\begin{array}{l}-0.061 \\
(0.027)\end{array}$ \\
\hline
\end{tabular}

Notes: OLS estimations consider departure rates and hiring rates by occupation for workers matched from the CPS to the LEHD firm sample. The CPS sample is a random sample taken during the 1986-1997 period; occupation is held fixed at that indicated to be the worker's primary occupation at the time of the CPS survey response. The sample considers native workers aged 20-65 in the observation year of the LEHD, comprising 132,507 person-year observations from 25,765 workers. Included workers have median annualized earnings during the 1995-2008 period of at least \$20,000. STEM occupations are designated as those related to computers, science and engineering, and mathematics. Salary splits are in real 2008 dollars on an annualized basis. Age fixed effects group workers into 20-29, 30-39, 40-49, 50-59, and 60+ years old. Regressions are unweighted and cluster standard errors by firm. In columns 1 and 2, differences across groups are not statistically significant. In columns 3 and 4, differences across salary levels for older workers are statistically significant at a 10\% level for STEM and non-STEM occupations; differences between older STEM and non-STEM workers are not statistically significant. 